\title{
Dendritic cell CD83 homotypic interactions regulate inflammation and promote mucosal homeostasis
}

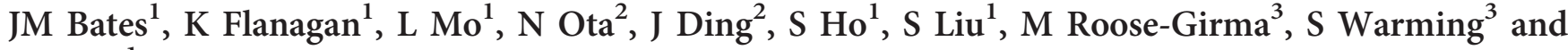 \\ L Diehl $^{1}$
}

Dendritic cells (DCs) form an extensive network in the intestinal lamina propria, which orchestrates the mucosal immune response. Alterations in DC function can predispose to inflammatory bowel disease, although by unknown mechanisms. We show that CD83, a highly regulated DC cell surface protein, modulates the immune response to prevent colitis. Mice with a conditional knockout of CD83 in DCs develop exacerbated colitis following dextran sodium sulfate challenge, whereas mucosal overexpression of CD83 inhibits DC inflammatory response and protects against colitis. These CD83 perturbations can be modeled in vitro where we show that CD83 homotypic interaction occurs via cell-cell contact and inhibits pro-inflammatory responses. CD83 knockdown or cytoplasmic truncation abrogates the effects of homotypic binding. We demonstrate that CD83 homotypic interaction regulates DC activation via the mitogen-activated protein kinase pathway by inhibiting $\mathrm{p} 38 \alpha$ phosphorylation. Our findings indicate that CD 83 homotypic interactions regulate DC activation and promote mucosal homeostasis.

\section{INTRODUCTION}

The mucosal immune system needs to coexist with and remain tolerant to an abundance of gut luminal antigens including commensal bacteria while retaining the capacity to effectively respond to pathogens. Loss of immune homeostasis is fundamental in driving the pathogenesis of inflammatory conditions, such as inflammatory bowel disease (IBD). Dendritic cells (DCs) are emerging as critical mediators of immune homeostasis through selective induction of immune responses. Disruptions in DC function result in autoimmune diseases in several mouse models. ${ }^{1-6}$

DCs act as sentinels of the immune system by sensing microbial antigens directly from the environment or by responding to factors secreted by other immune cell types to coordinate the immune response. ${ }^{7}$ Although long characterized as antigen-presenting cells with the unique ability to activate naive T cells, DCs are now known to also be important mediators of tolerance and immune homeostasis. ${ }^{8}$ DCs form a dense network in the lamina propria underlying the intestinal epithelium. These DCs function in immune surveillance through projection of transepithelial dendrites to sample the intestinal lumen, ${ }^{9-11}$ as well as through constitutive delivery of antigens to mesenteric lymph nodes ${ }^{12}$ to induce either tolerance or immune response. Though DCs are recognized as being critical to maintaining mucosal homeostasis, the mechanisms by which DCs sustain homeostasis have not been fully elucidated. Multiple mechanisms may contribute to DC regulation of immune tolerance, including DC apoptosis to limit DC accumulation and maintain self-tolerance, ${ }^{4,13}$ functionally distinct DC subsets that induce development of regulatory $\mathrm{T}$ cells, ${ }^{14}$ and intrinsic factors that maintain DCs in an immature state. ${ }^{1}$ Thus, identifying mechanisms regulating DC activation may be key in understanding how DCs control immune activation and homeostasis.

CD83 is a member of the immunoglobulin (Ig) superfamily that has primarily been reported as a marker of mature DCs. ${ }^{15,16}$ Among immune cells, stable surface expression of CD83 is only seen on DCs, but CD83 is transiently expressed on

${ }^{1}$ Department of Pathology, Genetech, South San Francisco, California, USA. ${ }^{2}$ Department of Immunology, Genetech, South San Francisco, California, USA and ${ }^{3}$ Department of Molecular Biology, Genentech, South San Francisco, California, USA. Correspondence: L Diehl (diehl.lauri@gene.com)

Received 24 September 2013; accepted 26 July 2014; published online 10 September 2014. doi:10.1038/mi.2014.79 
activated lymphocytes. ${ }^{17-20}$ Additionally, CD83 is expressed on thymic epithelial cells, where it functions in the development of $\mathrm{CD} 4 \mathrm{~T}$ cells. ${ }^{21} \mathrm{CD} 83$ has been implicated in immune regulation both in vitro and in vivo. A soluble form of CD83 is detected in human sera, likely as a result of proteolytic cleavage from activated DCs and B cells. ${ }^{22}$ Release of soluble CD83 (sCD83) has been shown in human cytomegalovirus-infected human monocyte-derived DCs (MDDCs) and sCD83 was found to inhibit mixed lymphocyte reactions in vitro. ${ }^{23}$ Others have reported immunosuppressive activity of $\mathrm{sCD} 83$ on DCs, including loss of expression of surface activation markers ${ }^{24}$ and inhibition of maturation-induced cytoskeletal changes. ${ }^{25}$ CD83 is implicated in immune suppression in vivo, as sCD83 prevents cardiac allograft rejection, ${ }^{26}$ and the development of experimental autoimmune encephalomyelitis. ${ }^{27}$ However, the mechanism of CD83 immune-modulating activities is unknown. We demonstrate for the first time a mechanism by which CD83 homotypic interaction regulates DC activation and aids in the maintenance of mucosal immune homeostasis.

\section{RESULTS}

\section{Loss of CD83 in DCs exacerbates colitis}

CD83 has been implicated in the regulation of inflammation, but as CD83 is expressed on a number of cell types, we created mice with DC-specific knockout $(\mathrm{KO})$ to examine the function of CD83 on DCs. Mice with a conditional knockout (CKO) allele of $C d 83$ were generated by flanking exon 3 with loxP sites (see Methods and Supplementary Figure S1 online), and $C d 83^{\mathrm{fl} / \mathrm{fl}}$ mice were then bred to mice with transgenic expression of Cre recombinase under control of the $C d 11 c$ promoter $(\operatorname{Itgax})^{28}$ to generate $\mathrm{Cd} 83^{\mathrm{fl} /+} ; \mathrm{Cd} 11 \mathrm{c}$-Cre animals. These mice were then crossed to produce mice deficient for CD83 in DCs $\left(C d 83^{\mathrm{fl} / \mathrm{fl}} ; C d 11 c-C r e\right) . C d 83^{\mathrm{fl} / \mathrm{fl}} ; C d 11 c$-Cre mice showed no gross morphological abnormalities and, unlike global Cd83 KO mice, ${ }^{21}$ had normal numbers of CD4 T cells in the spleen when compared with $C d 83^{\mathrm{wt} / \mathrm{wt}} ; \mathrm{Cd11}$ c-Cre littermates (Figure 1a). Total DC numbers in the spleen and colon were similar, but expression of CD83 was lost on most DCs in $C d 83^{\mathrm{fl} / \mathrm{fl}} ; \mathrm{Cd} 11 \mathrm{c}$-Cre mice (Figure $\mathbf{1 b}$ and data not shown). T-cell subsets in the colon lamina propria were also similar in $C d 83^{\mathrm{fl} / \mathrm{fl}} ; \mathrm{Cd} 11 \mathrm{c}$-Cre and $C d 83^{\mathrm{wt} / \mathrm{wt}} ; C d 11 c$-Cre littermates (see Supplementary Figure S2a-c). CD83 is expressed on all DC subsets in the intestinal lamina propria (see Supplementary Figure S3), and loss of CD83 expression also had no effect on the frequency of DC subsets in the colon lamina propria. $C d 83^{\mathrm{fl} / \mathrm{fl}} ; \mathrm{Cd} 11 \mathrm{c}$-Cre mice had similar numbers of the two principal DC subsets in the intestinal lamina propria, which are separated by expression of CD11b ( $\alpha_{\mathrm{M}}$ integrin) and differentially express CD103 $\left(\alpha_{\mathrm{E}}\right.$ integrin) (Figure 1c). ${ }^{29}$

If CD83 is important in DC regulation of immune homeostasis, we hypothesized that loss of CD83 in DCs would exacerbate inflammation in disease models. $C d 83^{\mathrm{fl} / \mathrm{fl}} ; C d 11 \mathrm{C}-\mathrm{Cre}$ and $C d 83^{\mathrm{wt} / \mathrm{wt}} ; \mathrm{Cd11c}$-Cre littermates were challenged with dextran sodium sulfate (DSS) to induce acute colitis. Loss of
CD83 expression in DCs resulted in decreased survival of mice after DSS challenge (Figure 1c). Cd83 $3^{\mathrm{fl} / \mathrm{fl}} ; C d 11 \mathrm{c}$-Cre DSStreated mice had severe weight loss, retaining significantly less of their initial body weight (77.7\%) compared with $C d 83^{\text {wt } / \text { wt }}$; Cd11c-Cre littermates (84.9\%) by day 8 (Figure 1d), thus requiring euthanasia of all but one $C d 83^{\mathrm{fl} / \mathrm{fl}} ; \mathrm{Cd} 11 \mathrm{c}$-Cre mice for humane reasons. Furthermore, DSS treatment resulted in overt blood present around the anus and in stools in $100 \%$ of the $C d 83^{\mathrm{f} / \mathrm{fl}} ; \mathrm{Cd11c}$-Cre mice by day 8 , but no bloody stool was observed in $C d 83^{\mathrm{wt} / \mathrm{wt}} ; C d 11 c$-Cre littermates (Figure 1e). In order to evaluate colitis scores, mice were treated with a reduced DSS concentration and euthanized on day 8 to allow for disease progression without death of animals prior to the study end point. $C d 83^{\mathrm{fl} / \mathrm{fl}} ; C d 11 c$-Cre animals had significantly increased histology scores compared with $C d 83^{\mathrm{wt} / \mathrm{wt}} ; C d 11 c^{-}$ Cre littermates (Figure 1f). These results show that DC CD83 expression mitigates DSS-induced colitis.

\section{CD83 overexpression results in decreased expression of surface maturation markers on lamina propria DCs}

Next, we sought to determine whether CD83 has an effect specifically at the intestinal mucosal surface. To study the role of CD83 in mucosal immune regulation, we ectopically expressed $C d 83$, driven under the fatty acid-binding protein (Fabp2) promoter, in the intestinal epithelium, allowing for the targeted delivery of intact CD83 extracellular domain at the mucosal surface in transgenic mice. CD83 expression is limited to gut-associated lymphoid tissue in wild-type (WT) animals but is ectopically expressed in the epithelial cells of the small intestine and colon of $\mathrm{Cd} 83 \mathrm{Tg}$ mice (Figure 2a). Overexpression in the mucosal epithelium allows for interaction of the CD83 extracellular domain with closely associated immune cells in the lamina propria. Cd83Tg mice showed no gross morphological differences and sCD83 was not detected in the serum of transgenic mice. As immune cells in the lamina propria are in close proximity to the mucosal epithelium, we sought to determine whether ectopic overexpression of CD83 in the mucosa affects the underlying immune cells. We isolated lamina propria mononuclear cells from the proximal colon of unchallenged $\mathrm{Cd} 83 \mathrm{Tg}$ and WT mice and analyzed them by fluorescenceactivated cell sorter (FACS). We found no differences in the number of DCs, T cells, or B cells between WT and Cd83Tg mice (see Supplementary Figure S4 and data not shown), and the relative proportions of naive and effector $\mathrm{T}$-cell subsets were also not affected (see Supplementary Figure S5). DCs isolated from the lamina propria of $\mathrm{Cd} 83 \mathrm{Tg}$ mice had significantly decreased expression of maturation markers, including CD83, CD86, and major histocompatibility complex class II (MHCII) (Figure 2b), while DCs isolated from the spleen showed no significant expression differences (Figure 2c). T cells isolated from the colon lamina propria of WT and $\mathrm{Cd} 83 \mathrm{Tg}$ mice showed no significant difference in CD44 expression, a marker of T-cell activation, in unchallenged mice (Figure 2d,e), suggesting that CD83 expressed on the epithelium interacted specifically with DCs. 
a

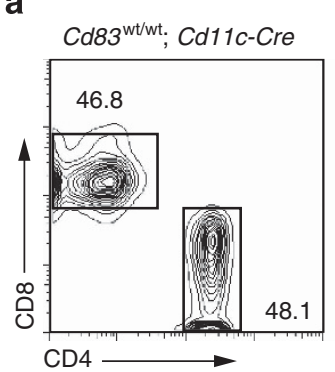

C $\quad C d 83^{\mathrm{wt} / \mathrm{wt}} ; \mathrm{Cd} 11 \mathrm{c}-\mathrm{Cre}$
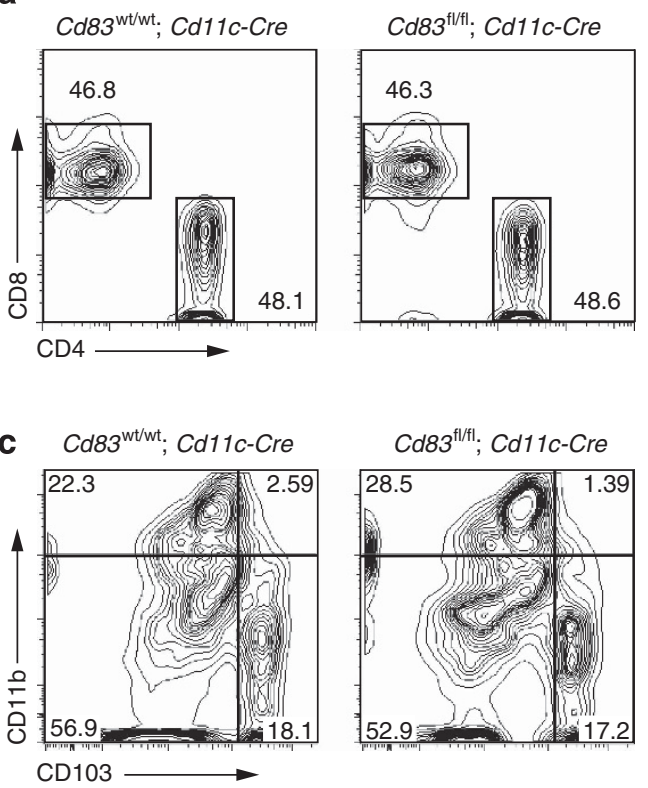

b

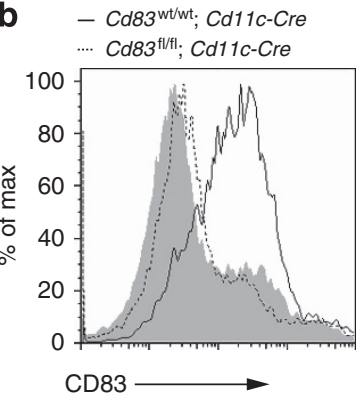

d

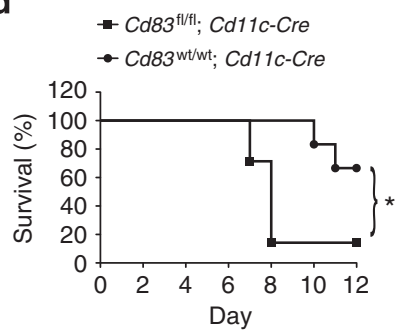

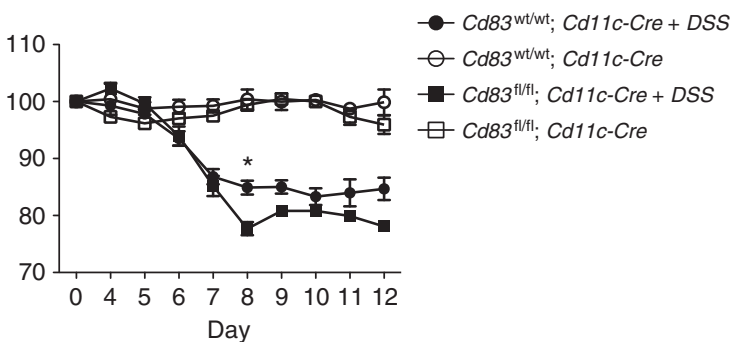

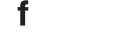

$\square$ Cd83 ${ }^{\text {wtwt. }}$ Cd11C-Cre $\square \mathrm{Cd} 83^{\mathrm{fl} / \mathrm{fl} ;}$; Cd11c-Cre

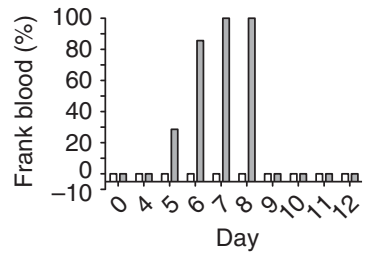

g

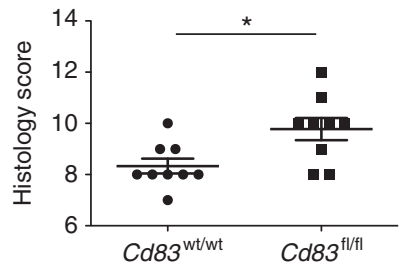

Figure 1 Knockout of CD83 in dendritic cells (DCs) exacerbates colitis. (a) Fluorescence-activated cell sorting (FACS) plots gated on T-cell receptor $\beta+$ lymphocytes in the spleen (see Supplementary Figure S2b). Cd83 $3^{\mathrm{fl} / \mathrm{ll}} ; \mathrm{Cd11c}$-Cre mice had 48.6\% CD4-positive T cells; Cd83 ${ }^{\mathrm{wt} / \mathrm{wt}} ; \mathrm{Cd11}$ c-Cre mice had $48.1 \%$ CD4-positive T cells in the spleen. (b, c) DCs were gated on CD11c + and MHCII + (see Supplementary Figure S2a). (b) Histograms showing relative expression of $\mathrm{CD} 83$ on splenic DCs of $\mathrm{Cd} 83^{\mathrm{wt} / \mathrm{wt}} ; \mathrm{Cd11} \mathrm{c}-\mathrm{Cre}$ (black line) and $\mathrm{Cd} 83^{\mathrm{fl} / \mathrm{fl}} ; \mathrm{Cd} 11 \mathrm{c}-\mathrm{Cre}$ (dashed line) mice. Solid gray histogram

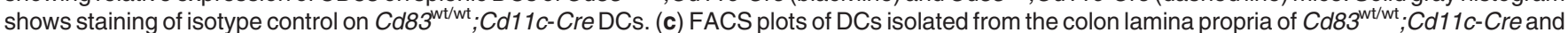
$C d 83^{\mathrm{fl} / \mathrm{fl}} ; \mathrm{Cd11} \mathrm{C}$-Cre mice. Mice had similar numbers of two main DC subsets, which differentially express CD103 and CD11b. (d) Colitis survival in Cd83 $3^{\mathrm{fl} / \mathrm{b}}$ ${ }^{\mathrm{fl}} ; \mathrm{Cd11} \mathrm{C}$-Cre $(n=7)$ and $C d 83^{\mathrm{wt} / \mathrm{wt}} ; \mathrm{Cd11}$ c-Cre mice $(n=6)$ treated with $3.5 \%$ dextran sodium sulfate. Cd83 conditional knockout animals had significantly decreased survival (Log-rank test, ${ }^{*} P=0.0186$ ). (e) Percentage of body weight retained following infection. Body weight at day 8 was significantly lower in $\mathrm{Cd} 83^{\mathrm{fl} / \mathrm{fl}} ;$; $111 \mathrm{c}$-Cre mice compared with $C d 83^{\mathrm{wt} / \mathrm{wt}} ; C d 11 \mathrm{c}$-Cre littermates. Data presented as mean \pm s.d. $\left({ }^{*} P=0.0025\right)$. (f) Incidence of frank blood surrounding the anus of animals. In all, $100 \%$ of $C d 83^{\text {fl/fl }} ; C d 11 \mathrm{c}$-Cre mice had frank blood surrounding the anus by day 7 . Frank blood was not observed in $C d 83^{\mathrm{wt} / \mathrm{wt}} ; \mathrm{Cd11} \mathrm{C}$-Cre littermates. (g) Histology scores at day 8 postinfection. Colitis score was significantly increased in $\mathrm{Cd} 83^{\mathrm{t} / \mathrm{fl}} ; \mathrm{Cd} 11 \mathrm{C}-\mathrm{Cre}$ mice $\left({ }^{\star} P=0.0159\right)$. Each dot represents a single animal.

\section{CD83 overexpression protects mice from DSS-induced colitis}

As CD83 overexpression suppressed inflammation in lamina propria DCs in unchallenged mice, we investigated whether increased local CD83 expression would protect mice from DSSinduced colitis. Although the kinetics of disease development was similar, Cd83Tg mice developed significantly less severe DSS-induced colitis than WT mice. WT mice lost more weight than Cd83Tg mice and had severe colitis marked by loss of colon architecture and increased inflammatory infiltrates (Figure 3a,b). Colon inflammation was less severe in Cd83Tg mice as evidenced by decreased histology scores (Figure 3c) as well as decreased serum cytokines, including interleukin (IL)-12p40 (also known as IL-12B) (Figure 3d a nd see Supplementary Figure S6). In addition, DC $I l 12 b$ expression was decreased in $C d 83 \mathrm{Tg}$ mice treated with DSS compared with WT animals on day 9, at the point of maximal weight loss (Figure 3e), indicating that increased mucosal CD83 levels modulate DC immune response to protect during colitis. These data demonstrate that local CD83 overexpression reduces inflammation in part due to inhibition of DC cytokine secretion.

\section{CD83 engages in homotypic binding}

The functional effects of CD83 on DCs in vitro, ${ }^{24,25}$ as well as efficacy we and others ${ }^{26,27,30}$ have seen in vivo, suggests that a ligand interaction ensues. Experiments with sCD83 have suggested putative ligands on monocytes ${ }^{31}$ and $\mathrm{DCs}^{24}$ as well as B cells and other antigen-presenting cells. ${ }^{17}$ Interestingly, all cell types that bind CD83 have also been shown to express 
a
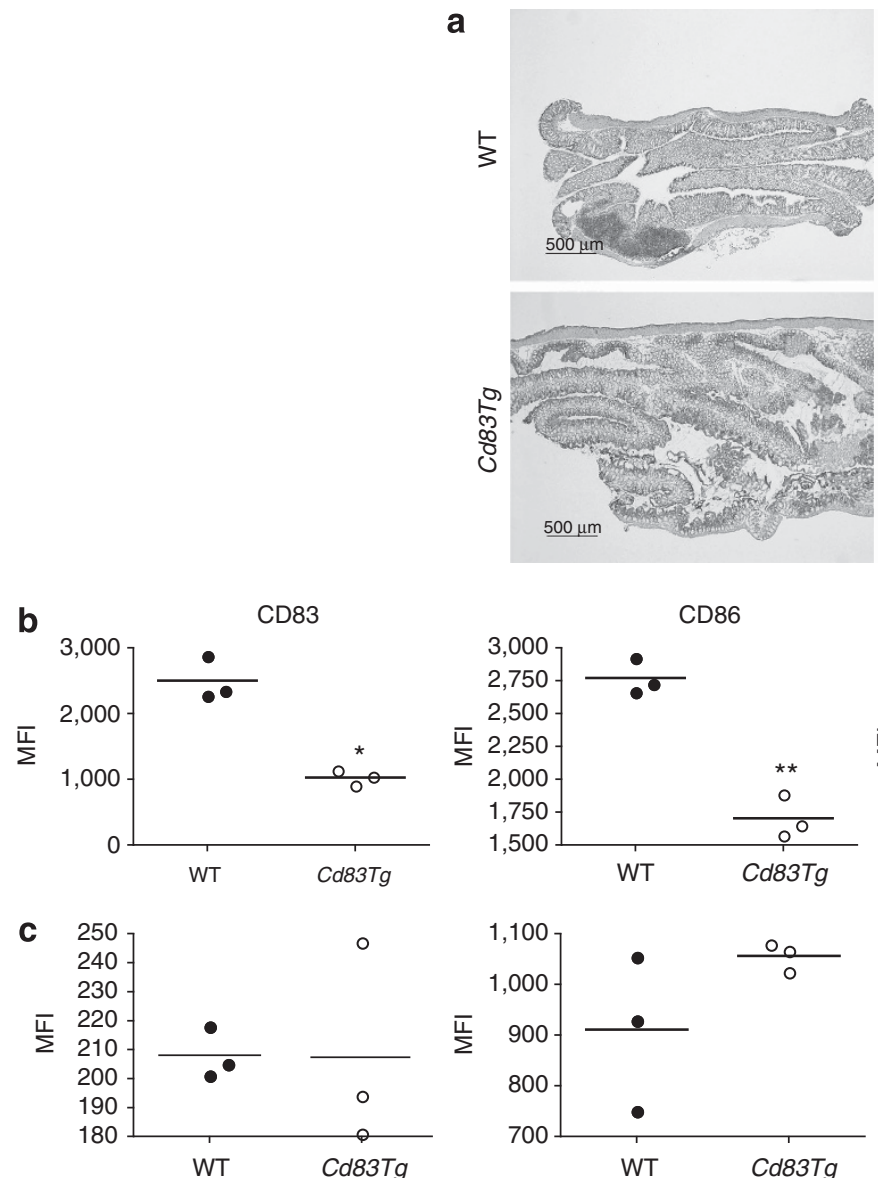
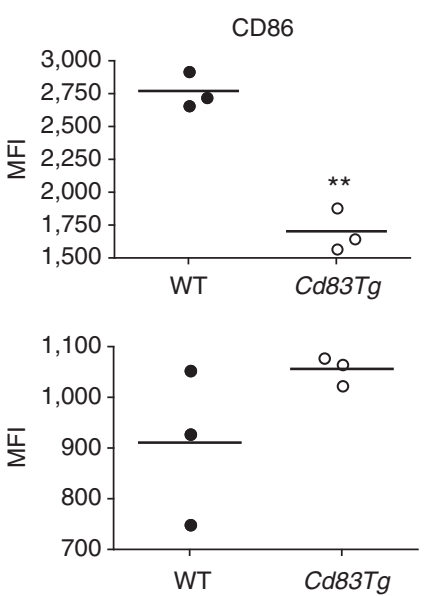
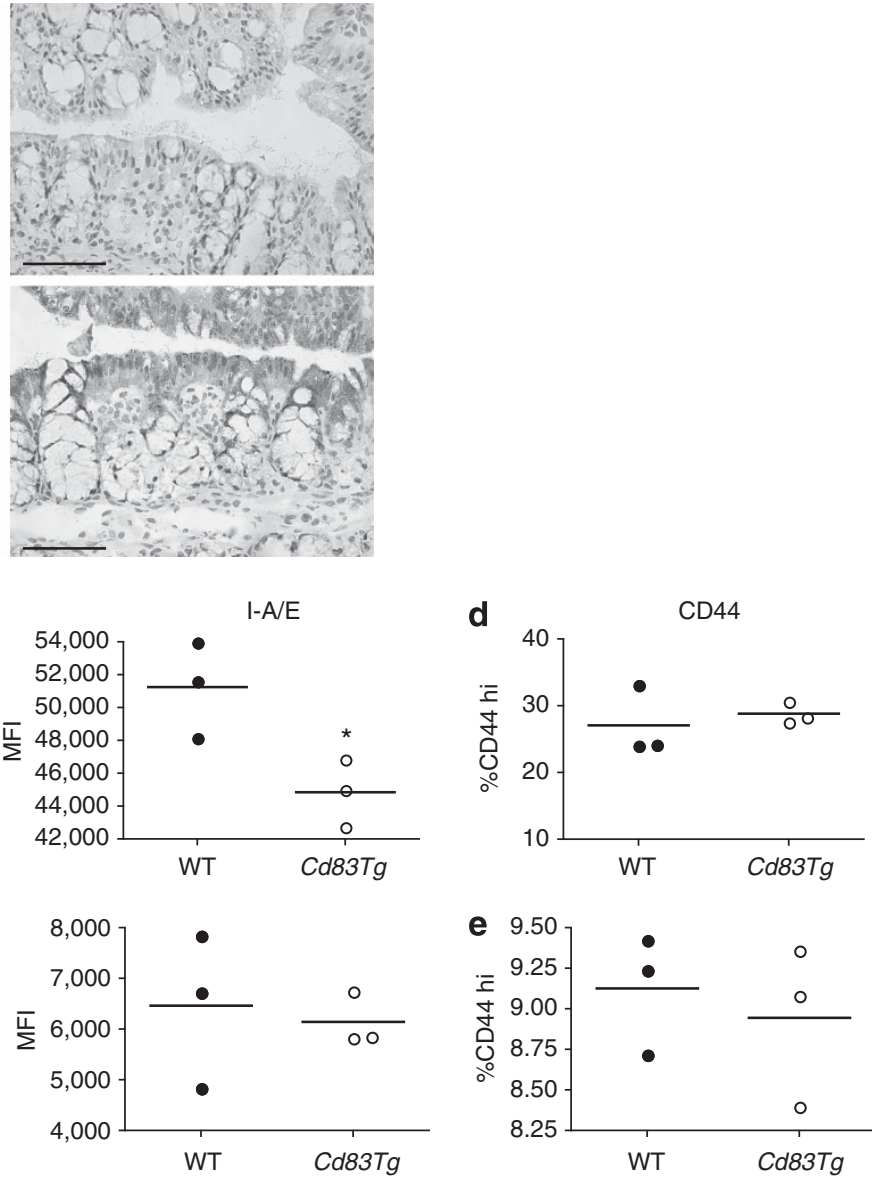

Figure 2 CD83 epithelial overexpression results in decreased expression of surface activation markers on colon lamina propria dendritic cells (LPDCs). (a) CD83 expression in wild-type (WT) animals is limited to gut-associated lymphoid tissue, but Cd83Tg mice show overexpression of CD83 in the epithelium. Left panels, bar $=500 \mu \mathrm{m}$. Right panels show higher magnification, bar $=50 \mu \mathrm{m}$. (b, c) Mean fluorescence intensity (MFI) of activation markers on the surface of DCs. (b) CD83, CD86, and MHCII (I-A/E) are significantly decreased on the surface of DCs isolated from the colon lamina propria. Bars indicate mean ( ${ }^{*} P=0.0182 ;{ }^{*} P=0.0032$ and ${ }^{*} P=0.0364$, respectively). (c) No difference seen in DCs isolated from the spleen. (d, e) T-cell activation. CD44 expression is not affected by overexpression of CD83 in the colon (d) or spleen (e). Each dot represents cells pooled from three animals, $n=9$ for each group.

CD83 at least transiently. To identify CD83 ligands, we performed a biased screen using a secreted protein microarray platform, ${ }^{32}$ which detected homotypic binding to CD83, but not other Ig proteins spotted on the arrays (data not shown).

To further investigate CD83 homotypic binding, we generated stable cell lines that express the full-length human CD83 (CHO-CD83) and looked for binding of sCD83.Fc chimeric protein by FACS. CD83 naturally exists as a dimer due to an unpaired cysteine residue at amino acid $129,{ }^{33}$ which is present and leads to dimerization of our CD83 protein expressed in $\mathrm{CHO}$ cells as well as our chimeric CD83.Fc protein (data not shown). Expression of human CD83 in CHO cells (Figure 4a) resulted in binding of phycoerythrin (PE)labeled CD83.Fc, not seen in the control cell line (Figure 4c). Stable expression of CD83 in CHO cells was also sufficient to cause aggregation of these cells while in suspension culture (see Supplementary Figure S7a,b), which could be blocked by the addition of sCD83.Fc protein but not an IgG.Fc control protein (see Supplementary Figure S7c,d). Additionally, we also found binding of CD83.Fc to mature MUTZ-3-derived DCs but very little binding to immature DCs, which express low levels CD83 on the surface (Figure $4 \mathbf{b}, \mathbf{d}$ ). Furthermore, binding of CD83.Fc could be blocked by preincubation with anti-CD83 antibody (Figure 4e). These data suggest that CD83 expression is sufficient for binding of the soluble protein. To confirm that binding of CD83.Fc was due to the expression of CD83 on the surface of the mature DCs, we used siRNAs to knock down CD83 expression in mature DCs (Figure 4f). Knockdown of CD83 resulted in the loss of surface expression on mature DCs (Figure $\mathbf{4 g}$ ) and a significant decrease in total protein (see Supplementary Figure S8) as well as decreased expression of MHCII, ${ }^{34}$ but no changes in other activation markers, such as CD86 (see Supplementary Figure S5e,f). Loss of CD83 surface expression completely abrogated the binding of CD83.Fc to mature DCs (Figure $4 \mathbf{h}$ ), indicating that surface expression of CD83 is necessary for binding. Additionally, this homotypic interaction was further confirmed by pulldown assay where CD83 in DC lysates were found in complex with CD83-GST 
a

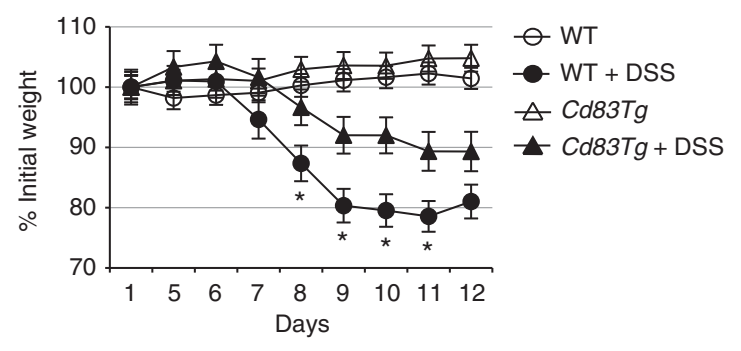

b

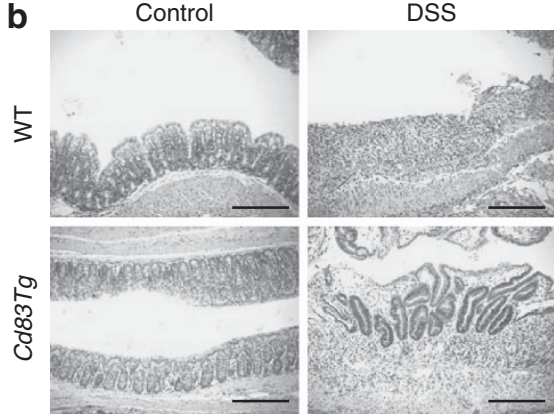

C

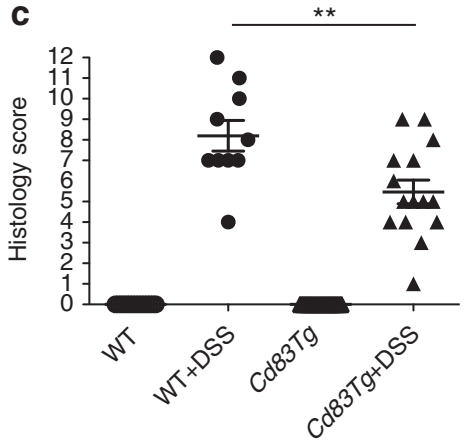

d

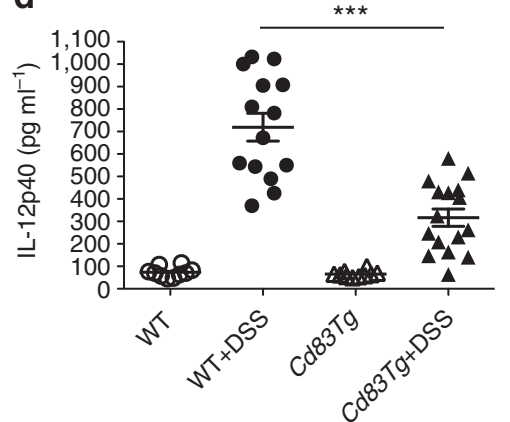

e

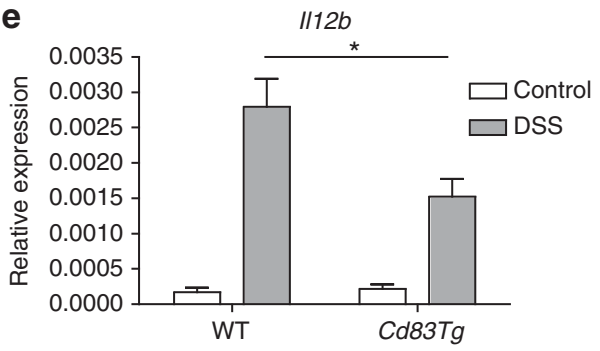

Figure 3 CD83 protects mice from dextran sodium sulfate (DSS)-induced colitis. (a) Decreased weight loss in Cd83Tg mice. Wild-type (WT) mice treated with $6 \%$ DSS lost $\sim 20 \%$ body weight, while Cd83Tg mice retained $\sim 89 \%$ initial body weight by day $12, n=15$ animals per group. Percenatge of body weight significantly decreased in WT mice compared with Cd83Tg littermates at days 8-11 ( $\left.{ }^{\star} P<0.0001\right)$. (b) Hematoxylin and eosin staining of colon sections. Scale bar indicates $200 \mu \mathrm{m}$. (c) Histology scores of WT and Cd83Tg mice. WT mice had mean colitis severity score of 8.2, while Cd83Tg was significantly lower $\left({ }^{\star *} P=0.0094\right)$ at 5.3. Each dot represents one animal. (d) Enzyme-linked immunosorbent assay of serum cytokine levels significantly decreased in Cd83Tg mice treated with 6\% DSS compared with WT littermates treated with 6\% DSS. Data presented as mean \pm s.e.m., each dot represents average of triplicates from one animal $\left.{ }^{* * \star} P<0.0001\right)$. (e) Quantitative PCR of purified colon lamina propria dendritic cells. $I L 12 b$ is significantly decreased in Cd83Tg mice treated with DSS compared with WT littermates. $n=11$ animals in WT + DSS group, $n=10$ animals in all other groups. Data presented as mean \pm s.d. $\left({ }^{\star} P=0.0315\right)$.

(glutathione $S$-transferase) fusion protein. (see Supplementary Figure S13).

\section{CD83 has anti-inflammatory effects on DCs in vitro}

Next we sought to determine the effects of CD83 on DCs in order to investigate the function of $\mathrm{CD} 83$ in DC immune regulation. MDDCs were generated from whole blood obtained from multiple donors. DCs were stimulated with a cytokine cocktail to drive maturation in the presence or absence of CD83.Fc. As previously reported in the literature, ${ }^{24}$ treatment with CD83.Fc decreased the expression of some activation markers on the surface of DCs (see Supplementary Figure S9a-c). Additionally, we found that ligation with the anti-CD83 antibody had similar effects to the CD83.Fc protein (see Supplementary Figure S9d-f). These effects were only seen when CD83 treatments were given to immature DCs together with the maturation stimulus (see Supplementary Figure S9g). As DCs are known to regulate immune response through the production of cytokines, we investigated whether CD83 affected cytokine secretion by DCs. We found that treatment with CD83.Fc coincident with the maturation stimulus altered DC cytokine secretion resulting in a decrease in the production of pro-inflammatory cytokines subunit beta of
IL-12p40, monocyte chemotactic protein-1 (MCP-1) (Figure 5a,b), and an increase in IL-1 receptor antagonist (IL-1RN) (Figure 5c), which binds the IL-1 receptor and blocks downstream inflammatory signaling. ${ }^{35,36}$

Ligation of CD83 with antibody had similar effects as CD83.Fc. Anti-CD83 antibody ( $\alpha$ CD83) significantly decreased the release of IL-12p40 and MCP-1 into the cell supernatant while increasing production of IL-RN (Figure $5 \mathbf{e}-\mathbf{g}$ ). Treatment with CD83.Fc or $\alpha \mathrm{CD} 83$ had no effect on the production of other inflammatory cytokines, including IL-8 (Figure 5d,h and data not shown). Additionally, some cytokines (IL-9, IL-12p70, IL-10, IL-1 $\beta$, and IL-7) were not produced in our culture conditions (data not shown). In order to determine whether CD83 functions similarly in mouse, we tested the effects of mouse CD83.Fc and anti-mouse CD83 antibody on bone marrow-derived DCs (BMDCs). Consistent with data seen in human, mouse BMDCs expressed lower levels of $I l 12 b$ when treated with murine CD83.Fc or anti-mouse CD83 antibody (see Supplementary Figure S10). These results indicate that CD83 did not inhibit all pathways of inflammation. Rather CD83 treatment affects specific immune signaling pathways leading to its effects on the secretion of specific inflammatory cytokines. 

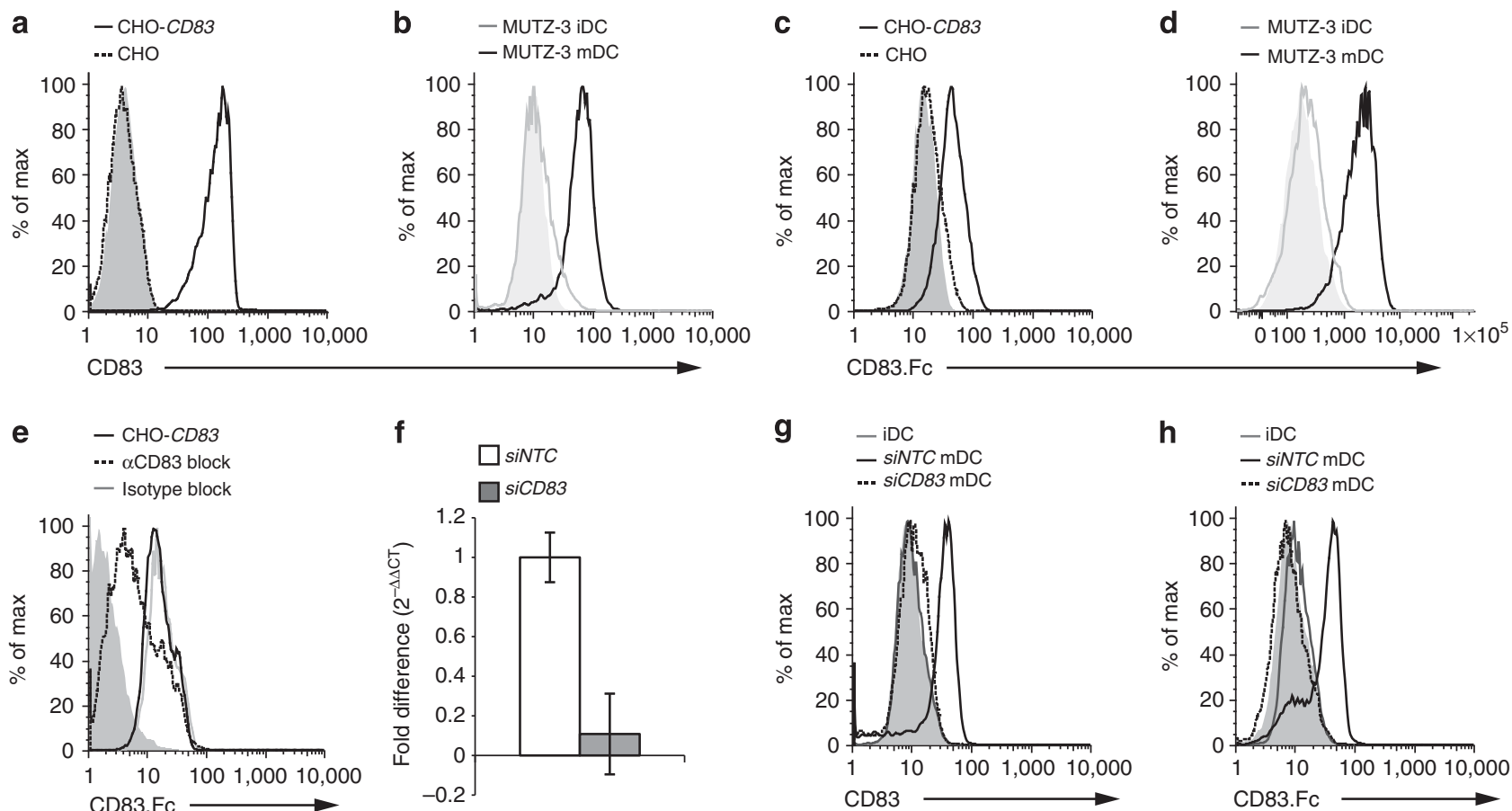

Figure 4 CD83 engages in homotypic binding at the cell surface. (a-d) CD83 binds to cells expressing CD83. (a, b) CD83 expression. (a) CD83 expressed on the surface of stably transfected CHO-hCD83 cells (black line) but not on control CHO cells (dashed line). (b) CD83 expressed on MUTZ-3derived mature dendritic cell (mDC; black line), but at very low levels on immature DC (iDC; gray line). Solid histograms represent isotype controls. (c, d) CD83.Fc binds to cells expressing CD83 on surface. (c) Binding of CD83.Fc to CHO-hCD83 (black line) but not to control CHO cells (dashed line). (d) CD83.Fc binds to surface of mDC (black), but not iDC (gray). Solid histograms in c and d represent binding with control hlgG1.Fc protein. (e) AntiCD83 antibody blocks binding to CHO-hCD83. CD83.Fc binds to CHO-hCD83 cells (black line); binding is blocked by $\alpha$ CD83 (dashed line), but not isotype control (gray line). Solid histograms in $\mathbf{e}$ and $\mathbf{h}$ represent binding with control hlgG1.Fc protein (f) CD83 siRNA efficacy. Taqman analysis of total RNA from MUTZ-3 mDCs treated with non-targeting control (siNTC) siRNA or siRNA specific to CD83 (siCD83), normalized to 18S. (g) CD83 is expressed on surface of $\mathrm{mDC}$ treated with siNTC (black line) but not on iDCs or mDCs treated with siCD83 (dashed line). (h) CD83.Fc binds to mDC; binding is abrogated by siCD83.
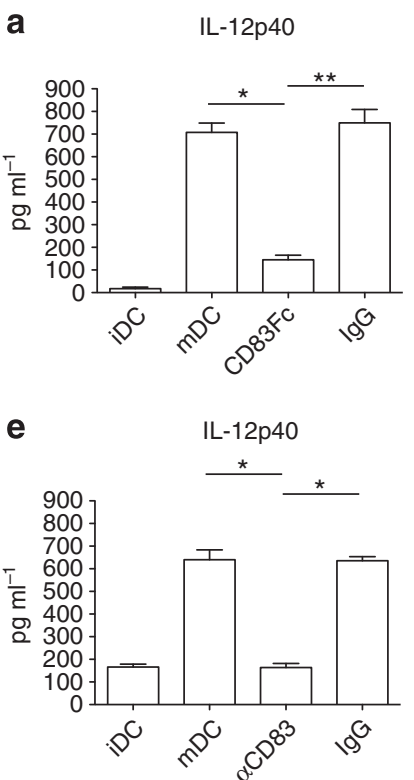

b

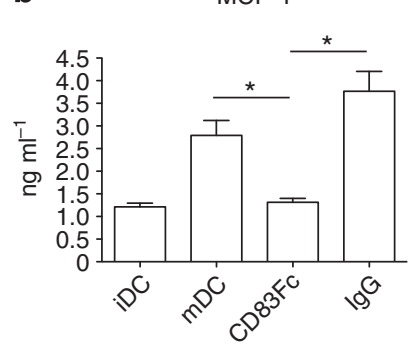

f

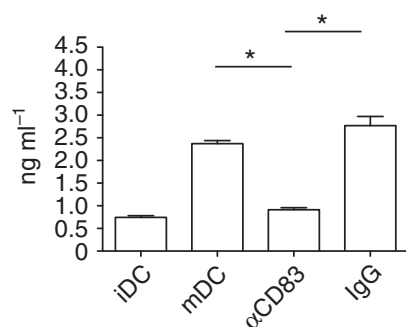

C

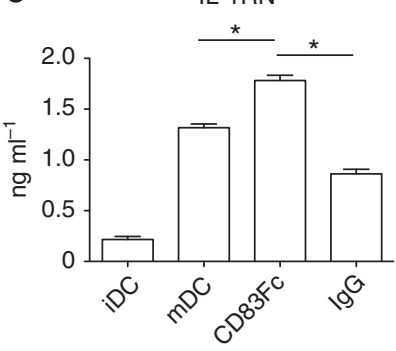

g

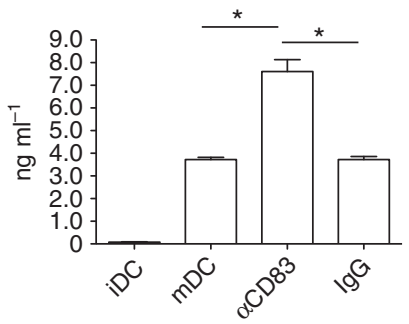

d

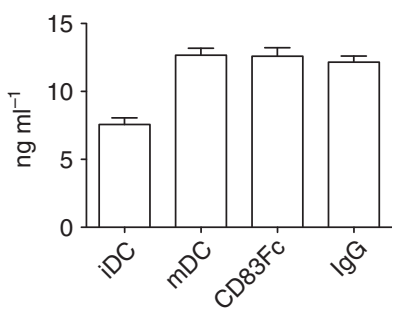

h

IL-8

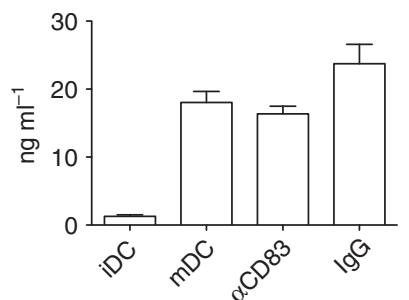

Figure 5 CD83 alters cytokine release in monocyte-derived dendritic cells (MDDCs). Enzyme-linked immunosorbent assay data of MDDC supernatants. Cytokine secretion is altered in MDDCs treated with $(\mathbf{a}-\mathbf{c})$ CD83. Fc and $(\mathbf{e}-\mathbf{g}) \alpha \mathrm{CD} 83$. Proinflammatory cytokines interleukin (IL)-12p40 $(\mathbf{a}, \mathbf{e})$ and monocyte chemotactic protein-1 (MCP-1) (b, f) are decreased upon CD83 treatment, whereas IL-1RN (c, g) secretion is increased. (d, h) No significant difference in IL-8 secretion. Data presented as mean \pm s.d. $\left({ }^{\star} P<0.01,{ }^{\star \star} P<0.001\right)$. Graphs are representative of five different donors. 

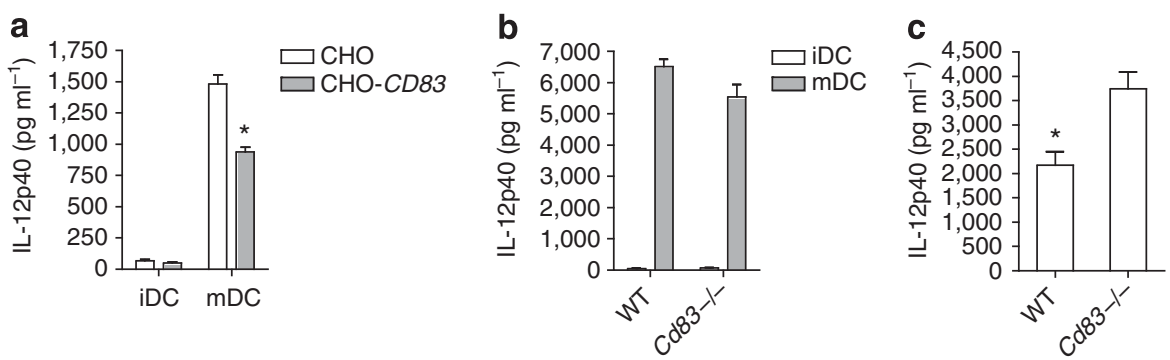

Figure 6 CD83 inhibits interleukin (IL)-12p40 cytokine production through cell-cell interaction. Enzyme-linked immunosorbent assays of cell culture supernatants. (a) Monocyte-derived dendritic cells co-cultured with $\mathrm{CHO}$ cells expressing human CD83 (gray bars) produce significantly less IL-12p40 upon stimulation with a cytokine cocktail than those co-cultured with a control $\mathrm{CHO}$ cell line (white bars); data presented as mean $\pm \mathrm{s} . \mathrm{d}$. ( ${ }^{\star} P=0.0218$ ). Results representative of data from three independent donors. (b) Mature bone marrow-derived DCs (BMDCs; gray bars) generated from Cd83 KO and wild-type (WT) littermates produce similar levels of IL-12p40 following $24 \mathrm{~h}$ lipopolysaccharide stimulation. (c) Co-culture of immature BMDCs with matured BMDCs from either WT or Cd83 knockout animals. Immature DCs cultured with WT mature BMDCs produced significantly less IL-12p40 than those cultured with CD83-deficient mature BMDCs, $P=0.0372$. Results representative of data from two independent experiments.

\section{CD83 inhibits DC inflammatory response through cell-cell interaction}

In normal homeostatic conditions in our mouse models, we found no evidence of sCD83 protein, suggesting that CD83 functions to maintain immune quiescence through cell-cell interaction. As DCs are present in an extensive network in the lamina propria, we hypothesized that the regulation of DC maturation and cytokine production may be a function of CD83 expression on DCs to inhibit bystander immature cells in order to prevent inappropriate inflammation and maintain homeostasis. In order to investigate whether cell-bound CD83 could lead to immune inhibition, we modeled these interactions by co-culture of immature human MDDCs with either the $\mathrm{CHO}$ control cell line or a $\mathrm{CHO}$ cell line expressing high levels of $\mathrm{CD} 83$ on the surface. $\mathrm{CHO}$ cells do not express CD14 or the human tumor nerosis factor (TNF) receptor, making it unlikely that this membrane CD83 is cleaved upon addition of lipopolysaccharide or TNF in the culture. Following stimulation, DCs co-cultured with $\mathrm{CHO}-\mathrm{CD} 83$ cells produced significantly less IL-12p40 than those co-cultured with the control cell line (Figure 6a), consistent with results using soluble protein (Figure 5a) and demonstrating that CD83 can produce antiinflammatory effects on DCs through cell-cell contact.

In order to determine whether this cell-to-cell mediated inhibition could also be observed in mouse, we investigated whether co-culture of immature BMDCs with mature BMDCs from WT but not CD83-deficient $\left(C d 83^{-/-}\right)$animals would inhibit IL-12p40 production. We generated mice with a $\mathrm{KO}$ allele of $C d 83$ starting from the same targeted embryonic stem (ES) cells as were used to generate our Cd83 CKO animals (see Methods). $C d 83^{-/-}$mice recapitulated the phenotype previously reported, ${ }^{21}$ and BMDCs generated from $C d 83^{-/-}$ mice produced cytokines at similar levels to those generated from WT littermates (Figure 6b and data not shown). We co-cultured fresh immature BMDCs from WT animals with BMDCs from either WT or $C d 83^{-1-}$ mice that had been previously cultured with lipopolysaccharide for $24 \mathrm{~h}$. These co-cultures were then stimulated for $24 \mathrm{~h}$ with lipopolysaccharide, and supernatants were collected and evaluated for IL-12p40 production by enzyme-linked immunosorbent assay (ELISA). Similar to the results from co-culture of human MDDCs, immature DCs co-cultured with mature DCs expressing high levels of CD83 produced significantly less IL-12p40 than those cultured with $C d 83^{-1-}$ mature DCs (Figure 6c). Thus CD83 expression on DCs can act to inhibit cytokine production of neighboring immature cells through cell-cell contact in both mouse and humans. These results are consistent with the idea that interactions among DCs in the lamina propria network can function to regulate immune homeostasis.

\section{CD83 mediates signaling to inhibit inflammation in DCs through the mitogen-activated protein kinase (MAPK) pathway}

CD83 homotypic interaction regulates DC activation and cytokine secretion to inhibit immune response. Moreover, knockdown of CD83 expression abrogated the effect of the soluble protein and $\alpha \mathrm{CD} 83$ antibody (Figure $7 \mathbf{a}$ and see Supplementary Figure S11a), indicating that the presence of cellular CD83 is not required for DC cytokine production but is required to mediate the anti-inflammatory effects of sCD83 treatment. To investigate whether CD83 is directly involved in signaling leading to an anti-inflammatory response, we used a lentiviral system to overexpress either a human full-length CD83 (CD83FL) or CD83 amino acids 1-171 resulting in membrane-bound CD83 with a truncated cytoplasmic domain ( $\Delta 172-205)$ in immature MUTZ-3-derived DCs (Figure $7 \mathbf{b}$ ). Following lentiviral infection and sorting of the top $10 \%$ of positive cells, DCs were analyzed by FACS for expression of surface activation markers. Infected DCs showed no increase in expression of maturation markers compared with non-infected controls (data not shown). Stimulation-induced IL-12p40 secretion was significantly reduced upon sCD83 or $\alpha \mathrm{CD} 83$ treatment in cells expressing full-length CD83. Loss of the cytoplasmic domain abolished CD83 inhibition of IL-12p40 secretion in cells following stimulation and treatment with 


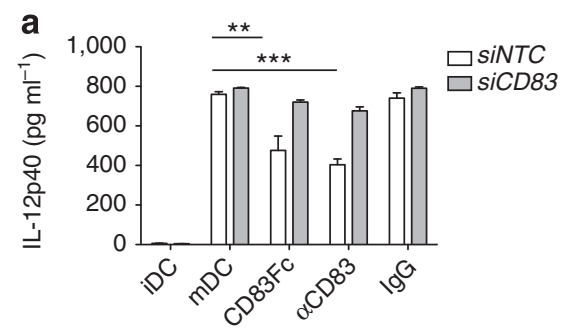

c
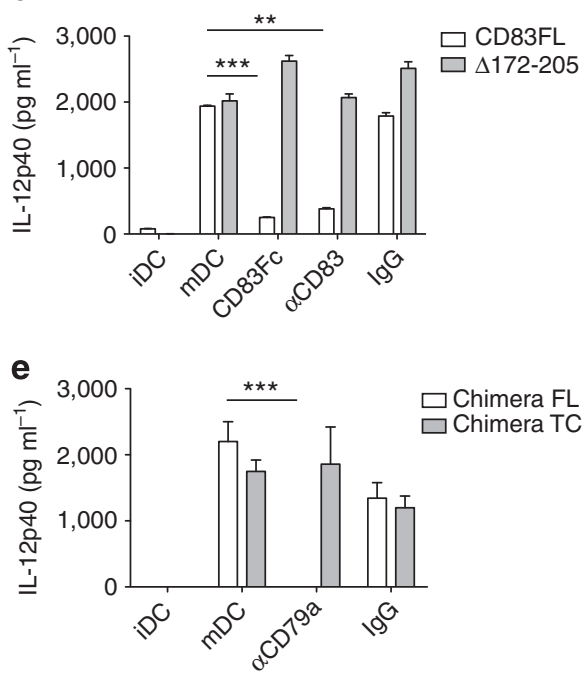

b

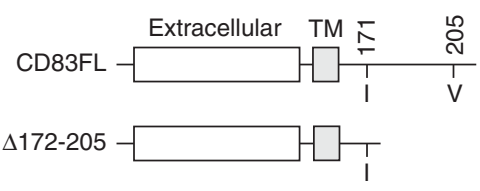

d
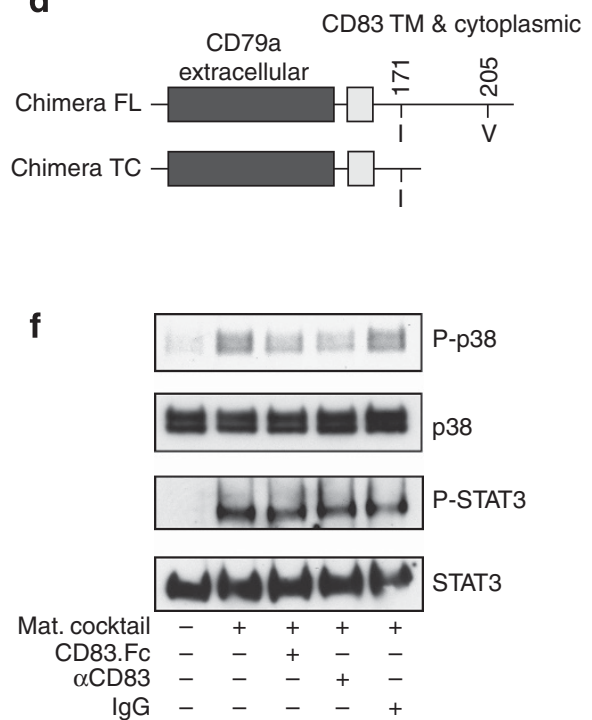

Figure 7 CD83 homotypic interaction mediates anti-inflammatory responses through p38 mitogen-activated protein kinase. (a) siRNA knockdown of CD83abrogates response to CD83.Fc or $\alpha$ CD83 antibody. Enzyme-linked immunosorbent assay (ELISA) of interleukin (IL)-12p40 shows CD83 required on surface of cells to mediate response. Double asterisks $\left(^{* \star}\right)$ indicate CD83.Fc is significantly different from mature dendritic cell (mDC) control, $P=0.0085$. Triple asterisks ${ }^{* * *}$ ) indicate $\alpha \mathrm{CD} 83$ is significantly different from $\mathrm{mDC}$ control, $P<0.0001$. (b) Truncated CD83 lentiviral expression constructs. (c) ELISA of IL-12p40 production. Lentiviral overexpression of full-length (FL) human CD83 does not inhibit MUTZ3 DC response to CD83; however, expression of the cytoplasmic truncated CD83 blocks inhibitory effect of CD83. Fc protein and $\alpha$ CD83 antibody. Triple asterisks $\left(^{* * *}\right)$ indicate CD83.Fc is significantly different from $\mathrm{mDC}$ control, $P<0.0001$. Double asterisks $\left({ }^{* *}\right)$ indicate $\alpha \mathrm{CD} 83$ is significantly different from mDC control, $P=0.0037$. (d) CD83 chimeric lentiviral expression constructs. Extracellular domain of CD79a fused to CD83 transmembrane region (TM) and FL or truncated cytoplasmic domain. (e) ELISA of IL-12p40 production. Lentiviral overexpression of FL chimera inhibits MUTZ3 DC response to anti-CD79a antibody, while expression of truncated chimera abrogates this response. Triple asterisks $\left.{ }^{\star * \star}\right)$ indicate anti-79a treated significantly different from control $\mathrm{mDC}, P<0.0001$. Cross-linking alone is sufficient to drive anti-inflammatory response through CD83 cytoplasmic domain. (a, $\mathbf{c}, \mathbf{e})$ Results representative of three independent experiments. (f) Western blots of monocyte-derived dendritic cell (MDDC) lysates show p38 and signal transducer and activator of transcription factor 3 (STAT3) phosphorylation upon stimulation and CD83 treatments for 5 min. Phosphorylation of p38 is decreased in cells treated with CD83.Fc or $\alpha$ CD83 antibody. No differences seen in phosphorylation of STAT3. Total p38 and total STAT3 used as a loading controls. Results representative of MDDCs generated from three independent donors.

CD83.Fc or $\alpha \mathrm{CD} 83$ (Figure 7c) and similar changes were seen in MCP secretion (see Supplementary Figure S1 1b), indicating that the CD83 cytoplasmic domain is required for signaling. As stimulation of the immature DCs would also induce the WT CD83 on the surface of the cells, our data suggests that the overexpression of truncated form acts as a dominant negative. To determine whether the CD83 cytoplasmic domain alone is sufficient to drive signaling, we used the lentiviral system to express a chimeric protein containing the extracellular domain of CD79a, an Ig family member not known to be involved in homotypic binding, fused to the transmembrane region, and either full-length (Chimera FL) or truncated (Chimera TC) form of the cytoplasmic domain of CD83 (Figure 7d). Crosslinking with anti-CD79a antibody was sufficient to drive signaling through the CD83 cytoplasmic domain, resulting in inhibition of IL-12p40 secretion in cells expressing the fulllength chimera. Anti-CD79a antibody had no effect on cells expressing the truncated chimera (Figure 7e). Again, similar effects were seen on MCP production (see Supplementary Figure S11c). Thus, the CD83 cytoplasmic domain mediates signaling to inhibit inflammatory response in DCs.

In order to understand how treatment with $\mathrm{sCD} 83$ protein or $\alpha \mathrm{CD} 83$ antibody blocks production of inflammatory cytokines, we screened for pathways that are altered following CD83 treatment. We used human phospho-kinase arrays (R\&D systems) to detect the relative phosphorylation of 46 kinase phosphorylation sites. Five-minute stimulation with the cytokine maturation cocktail led to phosphorylation of protein kinase B at threonine 308 (AKT T308), as well as the downstream p38 MAPK, which was reduced in cells treated 
with $\alpha \mathrm{CD} 83$ or sCD83 simultaneously with the maturation stimulus (see Supplementary Figure S12). MAPK signaling is known to be important for the production of IL-12p40, as specific inhibitors of p38 also block IL-12p40 production $^{37,38}$ and IL-12p40 production is defective in antigen-presenting cells from mice deficient in the MAPK kinase 3, a specific activator of p38 MAPK. ${ }^{39}$ Western blotting analysis of MDDCs treated with CD83.Fc or $\alpha \mathrm{CD} 83$ confirmed a decrease in phospho-p38 MAPK (Figure 7f). Phosphorylation in other pathways was not affected, including signal transducer and activator of transcription factor 3 , which is activated through TNF receptor binding, indicating that the effect of CD83 on the p38 MAPK pathway is specific (Figure 7f and data not shown). Thus CD83 homotypic interaction on DCs dampens MAPK activation during inflammatory signaling.

\section{Overexpression of CD83 increases sensitivity, whereas loss of CD83 on DCs leads to resistance to Citrobacter rodentium infection}

Our results suggest that DC CD83 homotypic interactions aid in maintaining homeostasis in part due to limiting IL-12p40 production. Thus we challenged our mice with a C. rodentium infection model of colitis to test this hypothesis. C. rodentium is an attaching and effacing pathogen, which induces transient distal colitis in immunocompetent mice and serves as a model of human infection with enterpathogenic Escherichia coli (EPEC) and enterhemorrhagic E. coli (EHEC). ${ }^{40}$ IL-23 is required for survival to $C$. rodentium ${ }^{41}$ and regulates IL-22 induction, which is responsible for early host defense to infection. ${ }^{42}$ As IL-23 shares the p40 subunit with IL-12, we

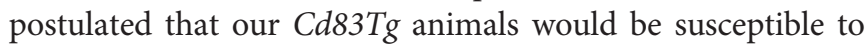
infection due to decreased production of IL-12p40 by colon lamina propria DCs. In contrast, we would expect that our $C d 83^{\mathrm{t} / \mathrm{fl}} ; \mathrm{Cd11c}$-Cre mice would have increased resistance to $C$. rodentium-induced colitis. Upon infection, we observed diarrhea and weight loss in both $\mathrm{Cd} 83 \mathrm{Tg}$ and WT littermates; however, disease-related survival was significantly decreased in Cd83 $\mathrm{Tg}$ mice (Figure 8a). Next, we isolated colon lamina propria DCs from WT and Cd83Tg mice 9 days postinfection and evaluated expression of IL-23p19 (Il23a). Il23a was significantly increased in WT animals following infection compared with control, non-infected mice. Cd83Tg colon lamina propria DCs expressed significantly less $I l 23 a$ at 9 days postinfection (Figure 8b). a
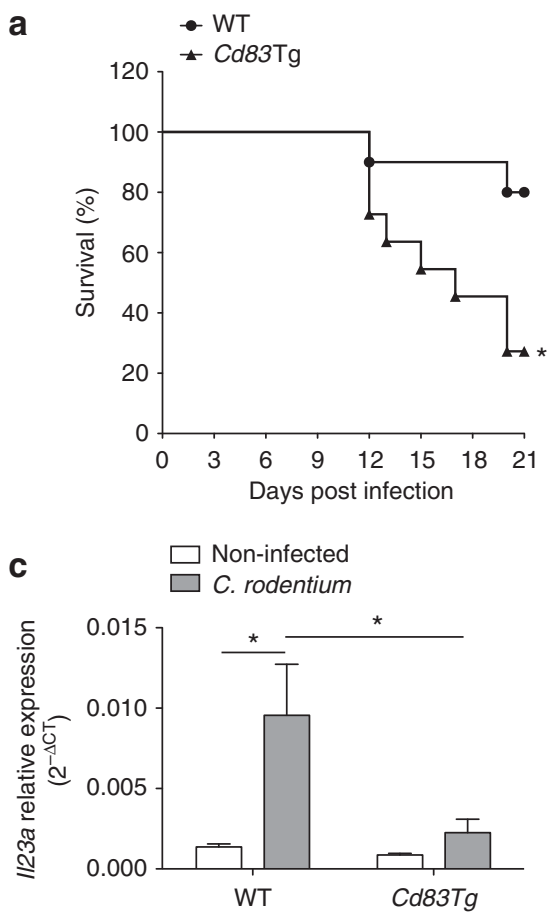

b
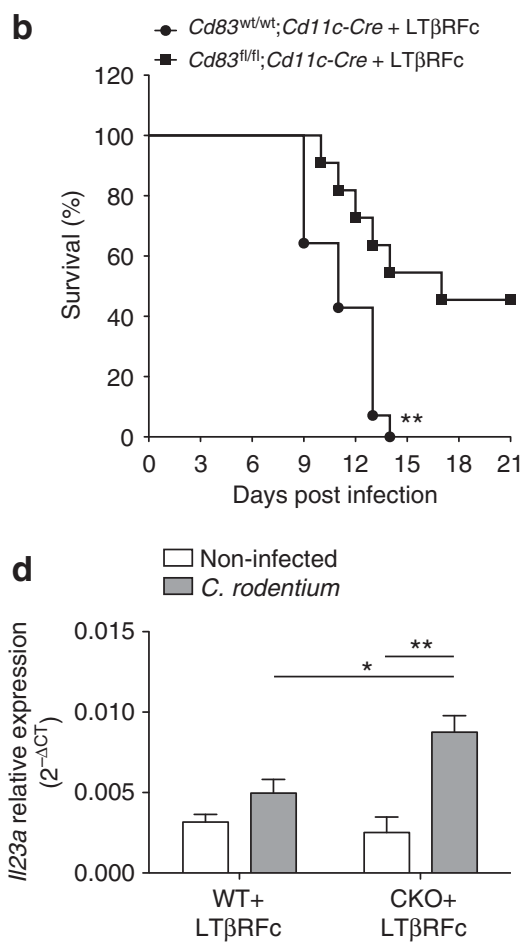

Figure 8 CD83 affects survival to $C$. rodentium infection. (a, c) C. rodentium infection survival curves. (a) Survival in wild-type (WT; $n=10)$ and $C d 83 T g$ $(n=11)$ animals infected with $C$. rodentium. Cd83Tg mice have significantly decreased survival $\left({ }^{*} P=0.0166\right.$, Log-rank test). (c) Survival in Cd83 ${ }^{\text {wt }}$ wt;

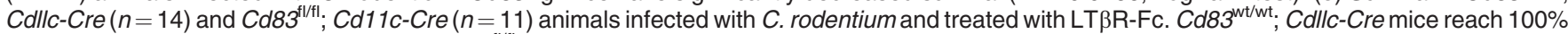
mortality by day 14 after infection, while Cd83 ${ }^{\text {fl/fl; }}$ Cd11c-Cre animals have significantly increased survival (** $P=0.0024$, Log-rank test). (b, d) II23a expression in isolated colon lamina propria dendritic cells (DCs). (b) Significant increase in II23a in DCs from WT animals 9 days afer infection with C. rodentium compared with non-infected WT controls $\left({ }^{*} P=0.0222\right)$. No significant difference between infected and non-infected control $C d 83 T g$ animals. DCs from infected WT animals also had significantly increased expression of II23a compared with Cd83Tg animals infected with $C$. rodentium

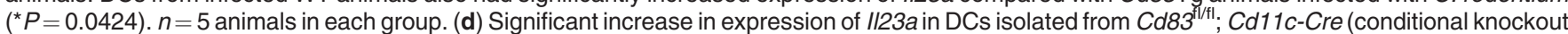
(CKO)) animals treated with LT $\beta R$-Fc 8 days after infection compared with non-infected CKO controls $\left.{ }^{* \star} P=0.003\right)$, while DCs from Cd83 ${ }^{\text {wt/wt }} ; C d l l c-C r e$ (WT) animals treated with LT $\beta R$-Fc showed no significant increase in expression following infection compared with non-infected WT controls. DC expression of II23a was significantly increased in infected CKO animals compared with WT animals infected with $C$. rodentium ( $\left.{ }^{\star} P=0.0175\right)$. $n=6$ animals per group. 
As WT animals typically resolve disease in 14-21 days, we needed an additional model that exacerbates colitis to examine whether CD83 on DCs contributes to immune pathogenesis of C. rodentium. Lymphotoxin $\left(\mathrm{LT} \alpha_{1} \beta_{2}\right) / \mathrm{LT} \beta$ receptor (LT $\beta \mathrm{R}$ ) signaling is another critical control for $C$. rodentium-induced colitis as indicated by increased disease-related mortality. ${ }^{43} \mathrm{We}$ blocked $\mathrm{LT} \alpha_{1} \beta 2 / \mathrm{LT} \beta \mathrm{R}$ signaling in $C d 83^{\mathrm{fl} / \mathrm{fl}} ; C d 11 c$-Cre and $C d 83^{\mathrm{wt} / \mathrm{wt}} ; C d 11 \mathrm{c}$-Cre mice by treatment with an antagonist lymphotoxin-beta receptor-Fc (LT $\beta R-F c) .{ }^{44}$ Following infection, $C d 83^{\mathrm{wt} / \mathrm{wt}} ;$ Cd11c-Cre mice had significantly increased disease severity culminating in $100 \%$ mortality at day 14 . Loss of CD83 in DCs led to increased resistance to infection as indicated by significantly increased survival in $C d 83^{\mathrm{f} / \mathrm{fl}} ; C d 11 c^{-}$ Cre mice (Figure 8c). In order to determine whether this increase in survival is due to an increase in IL23 production by DCs, we evaluated IL23a expression in colon lamina propria DCs of $C d 83^{\mathrm{fl} / \mathrm{fl}} ; \mathrm{Cd} 11 \mathrm{c}$-Cre and $\mathrm{Cd} 83^{\mathrm{wt} / \mathrm{wt}} ; \mathrm{Cd} 11 \mathrm{c}$-Cre treated with LT $\beta R-F c$ at 8 days postinfection. In contrast to mice overexpressing CD83, loss of CD83 in DCs led to a significant increase in IL23a expression compared with $C d 83^{\mathrm{wt} / \mathrm{wt}} ; C d 11 c$ Cre littermates (Figure 8d). These data support a novel mechanism of DC immune homeostasis through CD83 homotypic interaction.

\section{DISCUSSION}

DCs are increasingly being recognized as crucial mediators in maintaining immune homeostasis. Here we establish a novel mechanism of DC self-regulation through a CD83 homotypic interaction that inhibits immune response. This mechanism may help to explain how DCs in an immune reservoir such as the intestinal lamina propria prevent inappropriate inflammation and promote homeostasis in the presence of abundant commensal bacteria and non-pathogenic antigens present in the lumen.

Though CD83 has a well-documented role in T-cell development, ${ }^{21}$ its function on DCs is not well understood. We have discovered a specific role of CD83 in modulating DC inflammatory responses and cytokine production. Our findings that CD83 overexpression at the mucosal surface protects against DSS colitis and that loss of DC CD83 expression exacerbates colitis together show for the first time a role of CD83 on DCs in immune homeostasis. CD11c can be expressed at lower levels by other immune cells. Although we cannot rule out an effect of loss of CD83 on other immune cell types, the transient nature of CD83 expression on other immune cells together with our data showing specific effects of loss of CD83 on DCs suggests that it is CD83 expression on DCs that is important in our model. We saw a specific decrease in $I l 12 b$ in sorted DCs and no effects of CD83 on other immune cell types in our CD83 transgenic animals, and modulating IL-12p40 and IL-23p19 expression by DCs and hence IL-23 production had drastic effects on survival to $C$. rodentium. Furthermore, the worsened colitis in mice that lack CD83 specifically in DCs may provide insight into how decreased DC CD83 in the intestinal mucosa, which has been documented in Crohn's disease patients, ${ }^{45}$ may contribute to the poorly controlled mucosal inflammation and response to commensal bacteria characteristic of IBD.

Despite the multiple reports of immunosuppressive effects of sCD83 in vitro on DC morphology ${ }^{25}$ or in DC-mediated T-cell stimulation, ${ }^{23,24,46}$ and efficacy in vivo on cardiac ${ }^{26}$ and $\operatorname{skin}^{47}$ allograft rejection as well as efficacy in experimental autoimmune encephalomyelitis, ${ }^{27}$ no ligands have previously been identified for CD83. Evidence of CD83 ligand(s) have been demonstrated on DCs, ${ }^{24}$ monocytes, ${ }^{31}$ murine B cells, ${ }^{48}$ and CD8 ${ }^{+}$T cells. ${ }^{31,49}$ Our finding that CD83 binds DCs through a homotypic interaction is the first definitive identification of a ligand for CD83. Furthermore, we found that CD83 homotypic interactions occur through cell-cell contact, a method that may be employed within the vast network of mucosal DCs to regulate immune homeostasis. Although homotypic binding of CD83 is found on DCs, it cannot rule out that additional ligands could be present on other immune cell types.

We have identified functional effects of CD83 homotypic binding on DC cytokine secretion. We found that CD83 homotypic interaction can decrease DC secretion of MCP-1 and IL-12p40, cytokines known to be an important in mucosal inflammation. MCP-1 has been shown to be upregulated in mucosal tissues of both clinical ${ }^{50}$ and experimental IBD, and mice lacking MCP-1 show reduced severity and mortality to chemically induced colitis. ${ }^{51}$ IL-12p40 is also important in immune pathogenesis of IBD, ${ }^{52,53}$ contributes to increased $\mathrm{T}$ helper type $1 / 17$ response during inflammation, ${ }^{54}$ and antibodies to IL-12p40 have shown efficacy in murine models of colitis ${ }^{55,56}$ as well as active disease in patients. ${ }^{57}$ Thus treatment with CD83.Fc or anti-CD83 antibody in vitro results in immunosuppressive effects on DCs that are known to be important in innate immune regulation and mucosal homeostasis. Importantly, these immunosuppressive effects are only seen when immature DCs, which express low levels of CD83 due to CD83 cycling at the cell surface, ${ }^{58}$ encounter either soluble or cell-bound CD83, indicating that these effects would be restricted to incoming immature DCs in the lamina propria. Although soluble forms of CD83 have been previously reported to have immunosuppressive effects on mature DCs, including decreased CD83 expression on the surface of mature DCs ${ }^{24}$ we did not see this phenomenon. We believe these differences may be explained by the use of different forms of CD83 in our assays, as differences in CD83 proteins has led to widely varied efficacy in other models. ${ }^{20}$ Additionally, our findings that overexpression of CD83 reduces mucosal DC Il12b expression during colitis supports that $\mathrm{CD} 83$ homotypic interactions occur in vivo and may be a mechanism that DCs use to regulate inflammation.

The soluble form of CD83 has been reported at very low levels in normal human sera ${ }^{22}$ and interestingly increased in some forms of myeloid leukemia. ${ }^{59,60}$ We did not find evidence of sCD83 in our transgenic mice overexpressing CD83 in the intestinal epithelium. However, our data showing co-culture of immature DCs with cells expressing CD83 on their surface reduces IL-12p40 production and establishes that CD83 can regulate DC immune function through cell-cell interaction. 
This phenomenon also explains how overexpression of CD83 in the intestinal epithelium inhibits immune response, through interaction of CD83 expressed on intestinal epithelial cells with the closely associated DCs populating the lamina propria. In normal immune homeostasis, lamina propria DCs may sample luminal antigens in order to induce CD83 expression and modulate the immune environment to regulate adjacent DCs in the network. CD83 homotypic interaction on these DCs could function to keep inflammation localized and maintain immune quiescence. Furthermore, these results suggest that targeting DCs with anti-CD83 agonist antibody therapies may be useful to restore immune homeostasis by inhibiting $\mathrm{DC}$ activation by non-pathogenic bacteria as is seen in IBD.

As no ligands had been previously identified for CD83, likewise no mechanism of CD83 immune inhibition had been reported. We found that lentiviral overexpression of a cytoplasmic truncation of $\mathrm{CD} 83$ abolished the inhibitory effects of the sCD83.Fc protein and anti-CD83 antibody, whereas antibody cross-linking of a chimeric protein containing CD83 cytoplasmic domain led to inhibition of IL-12p40 secretion. These results demonstrate that the CD83 cytoplasmic domain is both necessary and sufficient to mediate signaling to direct immune regulation in DCs. Consistent with the decrease in IL-12p40 production, CD83 also specifically decreased activation of the p38 MAPK pathway, known to be necessary for IL-12p40 production as well as for expression of maturation markers in DCs. ${ }^{38}$ Thus CD83 homotypic interaction on DCs exerts a local control over inflammation by dampening MAPK activation during inflammatory signaling and would be limited to sites where there is a sufficient concentration of CD83expressing cells. A question which remains is what protein or which complexes bind to the CD83 cytoplasmic domain to intersect the MAPK pathway upstream of p38? Immune responses are often controlled through activating and inhibitory receptors on the immune cell surface, which regulate both the quality and magnitude of the response. Immune inhibition often depends on the presence of an immunoreceptor tyrosinebased inhibitory motif in the intracellular domain of these signaling proteins. However, CD83 does not contain an immunoreceptor tyrosine-based inhibitory motif domain, and other signaling motifs have not been identified in the CD83 cytoplasmic domain. Efforts to identify signaling motifs and CD83-binding partners are underway, hopefully providing additional insights into autoimmune pathology where DC homeostasis is perturbed.

\section{METHODS}

Generation of transgenic and KO mice. To generate the FABP.Cd83 transgene expression construct, we used the Picomax High-Fidelity PCR system (Agilent, Santa Clara, CA) to amplify the full-length mouse $C d 83 \mathrm{cDNA}$ from colon tissue and cloned this fragment into the FABP.sup.LacZ vector (Genentech, South San Francisco, CA) using the SpeI/SacII sites. The following primers were used (restriction sites are underlined): Cd83SPE-F: $5^{\prime}$-GATCAAACTAGTCCACCATGTC GCAAGGCCTCCAGCTCCT-3' and Cd83SACII-R: 5'-CATCATCC GCGGTCATACCGTTTCTGTCTTAGGAAG-3'. Following pronuclear microinjection, progeny from 72 founder mice were screened for high expression in the colon and low expression in the kidney. One transgenic founder mouse met these criteria and was used to generate the transgenic line after backcrossing to FVB/NJ (Jackson Labs, Bar Harbor, ME). The construct for targeting the mouse Cd83 locus in ES cells was made using a combination of recombineering ${ }^{61,62}$ and standard molecular cloning techniques. Briefly, a 7387-bp fragment (NCBI37/mm9 assembly, chr13: 43,889,315-43,896,701) from a C57BL/6 mouse BAC (RP23 library), was first retrieved into plasmid pBlight-TK. ${ }^{61}$ Second, a loxP-em7-kanamycin-loxP cassette was inserted upstream of exon 3 between position chr13: 43,892,711 and $43,892,712$. Correctly targeted plasmid was transformed into arabinose-induced SW106 cells (Cre expressing E.coli ${ }^{63,64}$ ) to remove kanamycin and leave behind a single loxP site. Finally, an frt-PGKem7-Neo-BGHpA-frt-loxP cassette was inserted downstream of exon 3 between position chr13: 43,893,684 and 43,893,685, resulting in the Cd83 CKO targeting vector. The final vector was confirmed by DNA sequencing. The $\mathrm{Cd} 83 \mathrm{CKO}$ vector that was linearized with NotI and C57BL/6 C2 ES cells ${ }^{65}$ were targeted using standard methods (G418 positive and gancyclovir negative selection). Positive clones were identified using PCR and taqman analysis and confirmed by sequencing of the modified locus. Correctly targeted ES cells were transfected with a Flp plasmid to remove Neo and create the Cd83 CKO or with a Cre plasmid to remove Neo and create the Cd83 KO allele. Cd83 KO or CKO ES cells were then injected into blastocysts using standard techniques, and germline transmission was obtained after crossing resulting chimaeras with $\mathrm{C} 57 \mathrm{BL} / 6 \mathrm{~N}$ females. Mice were housed in a specific pathogen-free barrier facility. All procedures were approved by the Genentech Animal Care and Use Committee.

DSS treatment. Mice at $8-10$ weeks of age were given DSS (MP Biomedicals, Santa Ana, CA) at the indicated concentrations ad libitum in drinking water for 7 days and at day 7 were switched to normal drinking water until cessation of experiment on day 12, unless otherwise specified. Mice were weighed on day 0 and daily from day 4 onwards and checked for occult blood, diarrhea, and any other abnormal signs. If weight loss exceeded $20 \%$ initial weight on day 0 , mice were euthanized. At day 12, mice were bled orbitally under anesthesia to collect 150-200 $\mu$ l blood, which generated $\sim 150 \mu \mathrm{l}$ sera. Sera cytokines were evaluated using the Bio-Plex Pro Mouse 23-Plex assay (Cat. No. M60-009RDPD; Bio-Rad, Hercules, CA) according to the manufacturer's instructions. Mice were then euthanized, and the small and large intestine was collected for histology. Intestines were sectioned and stained with hematoxylin and eosin for analysis. Sections were randomized and scored blind to group identification.

Infection with $\boldsymbol{C}$. rodentium and treatment. Infection with C. rodentium was performed as previously described. ${ }^{44}$ Briefly, C. rodentium was cultured in Luria broth overnight, and mice were inoculated orally with $2 \times 10^{9}$ colony-forming units of bacteria. Where indicated, mice were injected intraperitoneally three times per week with LT $\beta$ R-Fc $\left(150 \mu \mathrm{g} \mathrm{ml}^{-1}\right.$ per dose; PRO154527; Genentech).

Lamina propria leukocytes isolations and FACS analysis. Colons were harvested and flushed with cold Hank's Balanced Salt Solution (HBSS)/2\% fetal bovine serum (FBS)/10 mm 4-(2-hydroxyethyl)-1piperazineethanesulfonic acid (HEPES). Fat and other tissue associated with colon was removed, and the colons were rinsed with HBSS/ $2 \%$ FBS. Colons were cut longitudinally with scissors and transferred to a $50-\mathrm{ml}$ conical with $30-40 \mathrm{ml} \mathrm{HBSS} / 2 \%$ FBS on ice. Colon pieces were then transferred to a sterile baffled flask (Corning, Tewksbury, MA) with $10-15 \mathrm{ml}$ prewarmed HBSS/2\%FBS/10 mm HEPES/1 mм EDTA. Flasks were shaken at 200 r.p.m. for $45 \mathrm{~min}$ at $37^{\circ} \mathrm{C}$. Media was poured off, and the colons were washed in fresh HBSS/2\% FBS/10 mм HEPES and the remaining epithelia were scraped off using a blade. Colon was diced into $1-2-\mathrm{mm}$ pieces in RPMI containing $10 \%$ fetal calf serum, $20 \mathrm{~mm}$ HEPES, $0.5 \mathrm{mg} \mathrm{ml}^{-1}$ collagenase/dispase, and Pen/Strep, and then incubated for $45-90 \mathrm{~min}$ at $37^{\circ} \mathrm{C}$, with shaking at 200 r.p.m. Suspension was pipetted $4-5$ times and filtered through a $100-\mu \mathrm{m}$ 
filter, followed by 1800 r.p.m. spin for $10 \mathrm{~min}$ at $4{ }^{\circ} \mathrm{C}$. Cells were washed with RPMI containing 5\% FBS, $20 \mathrm{~mm}$ HEPES, and $0.1 \mathrm{mg} \mathrm{ml}^{-1}$ DNAse and filtered through a 70 -micron filter. Cells were then washed with FACS buffer and stained with antibodies for analysis of immune cells as well as sorting of DCs for RNA isolation and quantitative PCR.

Vector construction. The expression vector for $\mathrm{CHO}$ cells was derived from the neomycin-resistance plasmid, pRKneo, ${ }^{66}$ which contains the human cytomegalovirus promoter and enhancer and the simian virus 40 polyadenylation signal. A cDNA encoding N-terminally HIStagged full-length human CD83 (hCD83) was inserted into this expression vector using $\mathrm{XbaI} / \mathrm{XhoI}$ sites. All lentivirus expression vectors used in this study were derived from pGCMV.IRES.eGFP (pGIPZ derivative; Openbiosystems, Lafayette, CO), and constructs were made by PCR amplifying the full-length hCD83 gene (CD83FL) or amplifying a segment of the hCD83 gene, which truncates the cytoplasmic region $(\Delta 172-205)$ and inserting these fragments into the XhoI/EcoRI cloning sites. The following primers were used (restriction sites are underlined): CD83XhoI-F: $5^{\prime}$-ATCTCGAGCCACCATGTC GCGCGGCCTCCA- ${ }^{\prime}$ and CD83FLEcoRI-R: 5'-ACGAATTCTCAT $^{\prime}$ ACCAGTTCTGTCTTGTGA-3' ${ }^{\prime}$ or CD83 $\Delta 172$-205EcoRI-R: $5^{\prime}$-ACG AATTCTCAGATACTCTGTAGCCGTGCA- $3^{\prime}$. Chimeric constructs were made fusing the hCD79a extracellular domain to the CD83 transmembrane and cytoplasmic region. The lentivirus expression constructs were made by PCR amplifying the full-length chimera or a segment of the chimera, which truncated the cytoplasmic region as above, and inserting these into the XhoI/EcoRI cloning sites. The following primers were used: hCD79aXhoI-F: 5'-ATCTCGAGCCACCATGCCTGGGGGTCCAGG-3' ${ }^{\prime}$ with either the CD83FLEcoRI$\mathrm{R}$ or CD83 $172-205 \mathrm{EcoRI}-\mathrm{R}$ primers listed above. All products were amplified using the Expand high Fidelity PCR kit (Roche, Basel, Switzerland) and ligated with Rapid DNA ligation kit (Roche).

Derivation and culture of DCs from human monocytes and MUTZ-3 cells. Human whole blood was diluted with phosphate-buffered saline (PBS), layered on Ficoll histopaque (GE Healthcare, Fairfield, CT) and spun at 1500 r.p.m. for $30 \mathrm{~min}$. The leukocyte layer was removed and washed with PBS. Monocytes were isolated with Human monocyte isolation kit II (Miltenyi, Cologne, Germany). Monocytes were cultured for 6 days in RPMI/10\% FBS/ $1 \times$ pen/strep containing $125 \mathrm{ng} \mathrm{ml}^{-1}$ recombinant human interleukin 4 (rhIL-4) and $50 \mathrm{ng} \mathrm{ml}^{-1}$ recombinant human granulocyte/macrophage-colony stimulating factor (GM-CSF) (R\&D systems, Minneapolis, MN). The media was changed every other day to derive immature DC. MUTZ-3 cells were maintained in MEM $\alpha+$ Glutamax (GIBCO, Grand Island, NY)/20\% heat-inactivated FBS (Invitrogen, Grand Island, NY)/15\% HTB-9 conditioned media (described below) at a density of $0.5-1.5$ million $\mathrm{ml}^{-1}$. To derive immature DCs from MUTZ- 3 cells, cells were cultured in MEM $\alpha+$ Glutamax $/ 20 \%$ heat-inactivated FBS containing

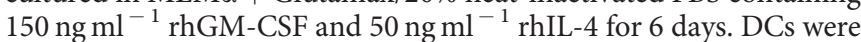
matured with a cytokine cocktail containing $25 \mathrm{ng} \mathrm{ml}^{-1}$ rhIL-1 $\beta$, $100 \mathrm{ng}-\mathrm{ml}$ rhIL-6, $50 \mathrm{ng} \mathrm{ml}^{-1} \mathrm{rhTNF} \alpha$, and $1 \mu \mathrm{g} \mathrm{ml}^{-1}$ PGE-2. All treatments with $10 \mu \mathrm{g} \mathrm{ml}^{-1} \mathrm{CD} 83 . \mathrm{Fc}_{\mathrm{c}}$ (in-house), $1 \mu \mathrm{g} \mathrm{ml}^{-1}$ antihuman CD83 antibody (HB15e; Santa Cruz, Dallas, TX), or antimouse CD83 antibody (in-house) were given simultaneously with the maturation stimulus. HTB-9 conditioned media was made by culturing HTB-9 cells ( $<$ passage 10) in RPMI/10\% FBS until they reach $80-90 \%$ confluency. Media was then replaced with fresh RPMI/10\% FBS and incubated for $48 \mathrm{~h}$. The supernatant was then collected and filtered through $0.2-\mu \mathrm{m}$ filter (Corning), aliquoted, and stored at $-20^{\circ} \mathrm{C}$.

Generation and culture of BMDCs. DCs were generated from mouse bone marrow as previously described. ${ }^{67}$ Briefly, bone marrow cells from mice were depleted of erythrocytes, T cells, B cells, granulocytes, and MHCII-positive cells and then cultured in RPMI (GIBCO) supplemented with $5 \%$ fetal calf serum, $10 \mathrm{~mm}$ HEPES, $20 \mu \mathrm{g} \mathrm{ml}^{-1}$ gentamycin, $50 \mu \mathrm{M} \beta$-mercaptoethanol, $100 \mathrm{ng} \mathrm{ml}^{-1}$ recombinant mouse GM-CSF (Cat No. 315-03; Peprotech, Rocky Hill, NJ), and $50 \mathrm{ng} \mathrm{ml}^{-1}$ recombinant mouse IL-4 (Cat. No. PMC0041; Invitrogen).

Flow cytometry. All cell types were analyzed by flow cytometry on a LSR II flow cytometer using the FACSDiva software (Becton Dickinson, Franklin Lakes, NJ). Cells were stained with fluorochrome and/ or biotin-conjugated antibodies to CD83, B7.1 (CD80), B7.2 (CD86), HLA-DR, I-A/E, CD11b, CD11c, CD103, CD44, T-cell receptor $\beta$, CD4, CD8, CD62L, B220, CD19 (BD Biosciences, San Jose, CA), F4/80 (Biolegend, San Diego, CA), PDCA-1 (eBioscience, San Diego, CA), and streptavidin conjugated to Alexa Fluor 405 (Invitrogen). Intracellular staining of Foxp3 transcription factor was done using anti-mouse/rat Foxp3 staining set (eBioscience). Isotype-matched antibodies were used to determine the level of non-specific staining.

$\mathrm{CHO}$ cell culture and generation of stable cell lines. $\mathrm{CHO}$ cells were cultured in RPMI/10\% FBS/2 mM L-glutamine. Cells were transfected with full-length hCD83.pRKneo using Fugene 6 (Roche). Top 10\% of CD83-positive cells were sorted by FACS, and stable cell lines were generated by limited dilution under selection with G418 $\left(400 \mu \mathrm{g} \mathrm{ml}^{-1}\right.$; GIBCO) to generate CHO.hCD83.

Labeling CD83.Fc with PE. CD83.Fc or IgG.Fc control was labeled with R-PE using Lightning-Link R-PE conjugation kit (Innova Biosciences, Cambridge, UK) according to the manufacturer's instructions. Briefly, $1 \mu \mathrm{LL}$-Modifier reagent was added for each $10 \mu \mathrm{l}$ protein and mixed gently. The protein sample was then pipetted directly onto the lyophilized Lightning-Link R-PE mix and incubated at $4{ }^{\circ} \mathrm{C}$ overnight in the dark. Following incubation, $1 \mu \mathrm{lLL}$-quencher reagent was added for every $10 \mu \mathrm{l}$ protein used, stored at $4{ }^{\circ} \mathrm{C}$, and the conjugate was used $30 \mathrm{~min}$ later.

CD83.Fc FACS binding assay. CHO.hCD83 cells were fixed in $4 \%$ paraformaldehyde for 5 min followed by washing with cold $1 \times$ PBS. Cells were resuspended in $\mathrm{PBS} / 2 \%$ bovine serum albumin $/ 2 \mathrm{~mm}$ EDTA (FACS buffer) and incubated with $1 \mu \mathrm{g}$ PE-labeled CD83.Fc or labeled control protein for $30 \mathrm{~min}$ on ice in the dark. Cells were washed with FACS buffer and analyzed by flow cytometry. Data analysis and construction of histograms showing total binding was done using the FlowJo v.8.4.5 (Ashland, OR).

CD83-GST pull down. A full-length CD83 was inserted into the PGEX4T-1 vector (GE Lifesciences, Piscataway, NJ), transformed into E.coli BL21 (Life Technologies, Grand Island, NY), and cultures were treated with IPTG to induce expression of the fusion protein. CD83GST fusion proteins were incubated with total cell lysates from MDDCs for $4 \mathrm{~h}$ at $4{ }^{\circ} \mathrm{C}$. Complexes were then bound to GST beads for $1 \mathrm{~h}$ at $4{ }^{\circ} \mathrm{C}$. Beads were washed four times, and fusion protein complexes were eluted with $10 \mathrm{~mm}$ reduced glutathione $/ 50 \mathrm{~mm}$ TrisHCL $\mathrm{pH}$ 8.0/5\% glycerol for $15 \mathrm{~min}$ at room temperature. Samples were run on a native gel and transferred to nitrocellulose for western blotting with anti-CD83 (clone D-3, Santa Cruz).

siRNA treatment. MUTZ-3 iDCs were generated as previously described except that cells were treated with Accell siRNAs targeting CD83 (Cat. No. E-012680; Dharmacon, Piscataway, NJ) or nontargeting controls (Cat. No. D-001910; Dharmacon) at day 4. siRNAs were resuspended in siRNA buffer (Cat. No. B-002000-UB-100; Dharmacon) at $100 \mu \mathrm{M}$. MUTZ-3 iDCs were incubated in Accell delivery media (Cat. No. B-005000; Dharmacon) supplemented with $3 \%$ heat-inactivated FBS, $150 \mathrm{ng} \mathrm{ml}^{-1} \mathrm{GM}-\mathrm{CSF}$, and $50 \mathrm{ng} \mathrm{ml}^{-1} \mathrm{IL}-4$ containing $10 \mu \mathrm{m}$ siRNAs at $37^{\circ} \mathrm{C}$ with $5 \% \mathrm{CO}_{2}$ for $72 \mathrm{~h}$. Knockdown was assessed by taqman quantitative PCR as well as western blotting of total cell lysates. At day 7, cells were treated and matured as previously described.

RNA isolation and quantitative PCR. RNA was isolated from all human and mouse cells using the RNeasy Plus mini kit (Qiagen, Venlo, The Netherlands). Quantitative real-time PCR (qRT-PCR) was 
performed using TaqMan One-Step RT-PCR Master Mix (ABI, Piscataway, NJ) and run on 384-well 7900HT platform using the SDS 2.0 software (Grand Island, NY). Thermal cycling conditions were $45 \mathrm{~min}$ at $50^{\circ} \mathrm{C}$ and $10 \mathrm{~min}$ at $95^{\circ} \mathrm{C}$, followed by 40 cycles of $1 \mathrm{~min}$ at $95^{\circ} \mathrm{C}$ and $1 \mathrm{~min}$ at $60^{\circ} \mathrm{C}$. All samples were amplified in triplicate. All TaqMan probes were ordered from ABI: CD83 (Cat. No. Hs00188486_m1), Il12b (Cat. No. Mm00434174_m1), Actin (Cat. No. 4352663), and GAPDH (Cat. No. 4352665). For each sample, the relative amount of target mRNA was expressed as $2^{-\Delta \mathrm{Ct}}$, where $\Delta \mathrm{C}_{\mathrm{t}}$ is determined by subtracting the average GAPDH $\mathrm{C}_{\mathrm{t}}$ value from the average $C D 83 \mathrm{C}_{\mathrm{t}}$ value or subtracting the average Actin $\mathrm{C}_{\mathrm{t}}$ value from the average $I l 12 b \mathrm{C}_{\mathrm{t}}$ value.

Aggregation assay. Aggregation studies were performed similarly to those previously described. ${ }^{68}$ Briefly, $\mathrm{CHO}$ cell lines were detached from flasks with $2 \mathrm{~mm}$ EDTA, washed and resuspended in HBSS- (No $\mathrm{Ca}_{2}+$ or $\left.\mathrm{Mg}_{2}+\right)$ containing 2\% FBS/10 mM EDTA. Cells were resuspended at $10^{6} \mathrm{ml}^{-1}$ and passed through a $70-\mu \mathrm{m}$ filter to obtain a single-cell suspension. Cells were then plated in suspension on low adhesion $10-\mathrm{cm}$ culture dishes and incubated at $37^{\circ} \mathrm{C}$ for $90 \mathrm{~min}$ on an orbital platform shaker. Paraformaldehyde (4\%) was then added to the cultures to fix cells for imaging.

ELISAs. For evalualtion of DC cytokine production, supernatants were collected after $48 \mathrm{~h}$ maturation of DCs. Secreted cytokines were analyzed by ELISA using MCP-1, IL-12p40, and IL-8 kits (Invitrogen), as well as IL-1RN (Cell Sciences, Canton, MA) according to the manufacturer's instructions. Presence of sCD83 was determined by sandwich ELISA. Plates were coated with $0.5 \mu \mathrm{g} \mathrm{ml}^{-1}$ Goat antimouse CD83 (R\&D Systems, Cat. No. AF1437) overnight at $4{ }^{\circ} \mathrm{C}$. Plates were washed with PBS, followed by blocking with $1 \%$ bovine serum albumin. Plates were incubated with standards (serial dilution of recombinant mouse CD83 (in-house), from 400 to $0.37 \mathrm{pg} \mathrm{ml}^{-1}$ ) and serum from Cd83Tg and WT littermates or supernatants from Cd83Tg and WT colon explant cultures overnight at $4{ }^{\circ} \mathrm{C}$. Following washing $3 \times$ with PBS, plates were incubated with $1 \mu \mathrm{g} \mathrm{ml}^{-1}$ Rat antimouse CD83 (R\&D Systems) in blocking buffer for $2 \mathrm{~h}$ at room temperature. Plates were washed as described previously, incubated at room temperature with Goat anti-rat-horseradish peroxidase (Santa Cruz Biotechnology, Cat. No. sc-2006) at 1:10,000 in blocking buffer for $1 \mathrm{~h}$, and again washed $3 \times$ with PBS. TMB substrate (Invitrogen) was added to wells for $15-30 \mathrm{~min}$ followed by stop solution (Invitrogen), and absorbance was measured at $450 \mathrm{~nm}$.

Luminex assay. Luminex bead assays were used to determine cytokine concentrations in mouse sera and human and mouse culture supernatants using Bio-Plex Pro Human Cytokine 27-plex Assays and Bio-Plex Pro Mouse Cytokine 23-plex Assays (Bio-Rad, nos. M500KCAF0Y and M60-009RDPD, respectively) according to the manufacturer's instructions.

Lentivirus production and infections. 293T cells were seeded at $1 \times 10^{7}$ on gelatinized $10-\mathrm{cm}$ culture dishes and allowed to grow for $\sim 20 \mathrm{~h}$ to reach $80-90 \%$ confluency. Media was aspirated and replenished with $5 \mathrm{ml}$ Dulbecco's modified Eagle's medium, 10\% FBS, and $2 \mathrm{~mm}$ L-glutamine. DNA mix was made combining $5 \mu \mathrm{g}$ expression plasmid, delta 8.9, and VSVG at a molar ratio of 1:2.3:0.2. Cells were transfected using Lipofectamine 2000 (Invitrogen) for $6 \mathrm{~h}$ at $37^{\circ} \mathrm{C}$. Transfection media was aspirated and replenished with $6 \mathrm{ml}$ normal growth media. Cells were incubated at $37^{\circ} \mathrm{C}$ for $\sim 40 \mathrm{~h}$. Supernatants were harvested, cleared by filtering through $0.45-\mu \mathrm{m}$ tube top filter (Corning), and concentrated using Lenti-X-concentrator (Clonetech, Mountain View, CA) according to the manufacturer's instructions. MUTZ-3 cells seeded at $0.5 \times 10^{6} \mathrm{ml}^{-1}$ in 24 well culture plates in MEM $\alpha+$ Glutamax (GIBCO Cat. No. 32571)/ $20 \%$ heat-inactivated FBS/15\% HTB-9 conditioned media (maintenance media). Polybrene was added to cells at a final concentration of $4 \mu \mathrm{g} \mathrm{ml}^{-1}$ and concentrated lentiviral supernatant at multiplicity of infection of 10. Cells were spun at 1800 r.p.m. in an Allegra X-12R tabletop centrifuge for $30 \mathrm{~min}$ at room temperature. After centrifugation, cells were incubated overnight at $37^{\circ} \mathrm{C}$. Media containing lentivirus was removed and replaced with fresh maintenance media. After 2-3 days of culture, the top $10 \%$ of green fluorescent proteinpositive cells were sorted and cultured in MEM $\alpha+$ Glutamax $/ 20 \%$ heat-inactivated FBS supplemented with $150 \mathrm{ng} \mathrm{ml}^{-1} \mathrm{rhGM-CSF}$ and $50 \mathrm{ng} \mathrm{ml}^{-1}$ rhIL-4 for 6 days and used as immature DCs. Cells were matured/treated with $\mathrm{CD} 83 . \mathrm{Fc}, \mathrm{HB} 15 \mathrm{e}$ and isotype control as described previously or with $1 \mu \mathrm{g}$ CD79a antibody (Santa Cruz) for $48 \mathrm{~h}$. Supernatants were collected, and IL12-p40 and MCP-1 were analyzed by ELISA.

Phosphokinase arrays and analysis. Human phospho-kinase arrays (R\&D systems) were performed according to the manufacturer's instructions. Briefly, MUTZ-3 DCs were washed with cold PBS and solubilized in Lysis Buffer 6 and rocked at $4{ }^{\circ} \mathrm{C}$ for $30 \mathrm{~min}$. Lysates were centrifuged at $14,000 \mathrm{~g}$ for $5 \mathrm{~min}$, and the supernatant was transferred to a new tube. Total protein was analyzed by Bradford (Bio-Rad). Array membranes containing 46 antibodies spotted in duplicates were blocked for $1 \mathrm{~h}$ at room temperature and then incubated with diluted cell lysate overnight at $4{ }^{\circ} \mathrm{C}$. Membranes were washed and then incubated with detection antibodies for $2 \mathrm{~h}$ at room temperature. Following washing, membranes were incubated in Streptavidinhorseradish peroxidase for $30 \mathrm{~min}$ at room temperature and washed again prior to detection with ECL + reagents (Amersham, Piscataway, NJ). Membranes were exposed on FUJI FILM Image Reader LAS-3000, and the average intensity was analyzed by Multi Gauge v3.1 (FUJI FILM, Edison, NJ).

Statistical analysis. Data are presented as mean \pm s.d. unless otherwise specified in the figure legend. The statistical significance of differences between groups was measured by the Student's $t$ test. Statistical significance of the difference between group survival was measured by the Log-rank test. $P$-values $<0.05$ were considered significant.

SUPPLEMENTARY MATERIAL is linked to the online version of the paper at http://www.nature.com/mi

\section{ACKNOWLEDGMENTS}

We thank Robert J. Newman for help with vector construction, Xin Rairdan for performing blastocyst injections, and Alfred Wong for excellent mouse colony management. Special thanks to Wenjun Ouyang, Naruhiso Ota, Eric Brown, John Lowe, Ira Mellman, and Marjie Van Hoy for scientific input and technical support.

\section{DISCLOSURE}

All authors are or were full-time employees of Genetech and may hold stock in the company.

(c) 2015 Society for Mucosal Immunology

\section{REFERENCES}

1. Dissanayake, D. et al. Nuclear factor-kappaB1 controls the functional maturation of dendritic cells and prevents the activation of autoreactive T cells. Nat. Med. 17, 1663-1667 (2011).

2. Hammer, G.E. et al. Expression of $\mathrm{A} 20$ by dendritic cells preserves immune homeostasis and prevents colitis and spondyloarthritis. Nat. Immunol. 12, 1184-1193 (2011).

3. Stranges, P.B. et al. Elimination of antigen-presenting cells and autoreactive $T$ cells by Fas contributes to prevention of autoimmunity. Immunity 26, 629-641 (2007).

4. Chen, M. et al. Dendritic cell apoptosis in the maintenance of immune tolerance. Science 311, 1160-1164 (2006).

5. Deane, J.A. et al. Control of toll-like receptor 7 expression is essential to restrict autoimmunity and dendritic cell proliferation. Immunity $27,801-810$ (2007). 
6. Blanco, P., Palucka, A.K., Gill, M., Pascual, V. \& Banchereau, J. Induction of dendritic cell differentiation by IFN-alpha in systemic lupus erythematosus. Science 294, 1540-1543 (2001).

7. Pulendran, B., Tang, H. \& Manicassamy, S. Programming dendritic cells to induce $\mathrm{T}(\mathrm{H}) 2$ and tolerogenic responses. Nat. Immunol. 11, 647-655 (2010).

8. Wallet, M.A., Sen, P. \& Tisch, R. Immunoregulation of dendritic cells. Clin. Med. Res. 3, 166-175 (2005).

9. Chieppa, M., Rescigno, M., Huang, A.Y. \& Germain, R.N. Dynamic imaging of dendritic cell extension into the small bowel lumen in response to epithelial cell TLR engagement. J. Exp. Med. 203, 2841-2852 (2006).

10. Niess, J.H. et al. CX3CR1-mediated dendritic cell access to the intestinal lumen and bacterial clearance. Science 307, 254-258 (2005).

11. Rescigno, M. et al. Dendritic cells express tight junction proteins and penetrate gut epithelial monolayers to sample bacteria. Nat. Immunol. 2, 361-367 (2001).

12. Huang, F.P. et al. A discrete subpopulation of dendritic cells transports apoptotic intestinal epithelial cells to $T$ cell areas of mesenteric lymph nodes. J. Exp. Med. 191, 435-444 (2000).

13. Chen, M., Felix, K. \& Wang, J. Critical role for perforin and Fas-dependent killing of dendritic cells in the control of inflammation. Blood 119, 127-136 (2011).

14. Coombes, J.L. et al. A functionally specialized population of mucosal CD103 + DCs induces Foxp3 + regulatory T cells via a TGF-beta and retinoic acid-dependent mechanism. J. Exp. Med. 204, 1757-1764 (2007).

15. Zhou, L.J., Schwarting, R., Smith, H.M. \& Tedder, T.F. A novel cell-surface molecule expressed by human interdigitating reticulum cells, Langerhans cells, and activated lymphocytes is a new member of the lg superfamily. $J$. Immunol. 149, 735-742 (1992).

16. Zhou, L.J. \& Tedder, T.F. Human blood dendritic cells selectively express CD83, a member of the immunoglobulin superfamily. J. Immunol. 154, 3821-3835 (1995).

17. Kretschmer, B., Luthje, K., Schneider, S., Fleischer, B. \& Breloer, M. Engagement of CD83 on B cells modulates B cell function in vivo. J. Immunol. 182, 2827-2834 (2009).

18. Wolenski, M. et al. Expression of CD83 in the murine immune system. Med. Microbiol. Immunol. 192, 189-192 (2003).

19. Breloer, M. et al. CD83 is a regulator of murine B cell function in vivo. Eur. J. Immunol. 37, 634-648 (2007).

20. Prazma, C.M., Yazawa, N., Fujimoto, Y., Fujimoto, M. \& Tedder, T.F. CD83 expression is a sensitive marker of activation required for B cell and CD4 + T cell longevity in vivo. J. Immunol. 179, 4550-4562 (2007).

21. Fujimoto, Y. et al. CD83 expression influences CD4 + Tcell development in the thymus. Cell 108, 755-767 (2002).

22. Hock, B.D., Kato, M., McKenzie, J.L. \& Hart, D.N. A soluble form of CD83 is released from activated dendritic cells and B lymphocytes, and is detectable in normal human sera. Int. Immunol. 13, 959-967 (2001).

23. Senechal, B., Boruchov, A.M., Reagan, J.L., Hart, D.N. \& Young, J.W. Infection of mature monocyte-derived dendritic cells with human cytomegalovirus inhibits stimulation of T-cell proliferation via the release of soluble CD83. Blood 103, 4207-4215 (2004).

24. Lechmann, M. et al. The extracellular domain of CD83 inhibits dendritic cell-mediated T cell stimulation and binds to a ligand on dendritic cells. J. Exp. Med. 194, 1813-1821 (2001).

25. Kotzor, N., Lechmann, M., Zinser, E. \& Steinkasserer, A. The soluble form of CD83 dramatically changes the cytoskeleton of dendritic cells. Immunobiology 209, 129-140 (2004).

26. Ge, W. et al. Immunosuppression involving soluble CD83 induces tolerogenic dendritic cells that prevent cardiac allograft rejection. Transplantation 90, 1145-1156 (2010).

27. Zinser, E., Lechmann, M., Golka, A., Lutz, M.B. \& Steinkasserer, A. Prevention and treatment of experimental autoimmune encephalomyelitis by soluble CD83. J. Exp. Med. 200, 345-351 (2004).

28. Caton, M.L., Smith-Raska, M.R. \& Reizis, B. Notch-RBP-J signaling controls the homeostasis of CD8- dendritic cells in the spleen. J. Exp. Med. 204, 1653-1664 (2007).

29. Denning, T.L., Wang, Y.C., Patel, S.R., Williams, I.R. \& Pulendran, B. Lamina propria macrophages and dendritic cells differentially induce regulatory and interleukin 17-producing Tcell responses. Nat. Immunol. 8, 1086-1094 (2007).

30. Wilson, J. et al. Antibody to the dendritic cell surface activation antigen CD83 prevents acute graft-versus-host disease. J. Exp. Med. 206, 387-398 (2009).

31. Scholler, N., Hayden-Ledbetter, M., Hellstrom, K.E., Hellstrom, I. \& Ledbetter, J.A. CD83 is an I-type lectin adhesion receptor that binds monocytes and a subset of activated CD8 $+\mathrm{T}$ cells [corrected]. J. Immunol. 166, 3865-3872 (2001).

32. Ramani, S.R. et al. A secreted protein microarray platform for extracellular protein interaction discovery. Anal. Biochem. 420, 127-138 (2012).

33. Lechmann, M., Kotzor, N., Zinser, E., Prechtel, A.T. \& Steinkasserer, A. CD83 is a dimer: Comparative analysis of monomeric and dimeric isoforms. Biochem. Biophys. Res. Commun. 329, 132-139 (2005).

34. Tze, L.E. et al. CD83 increases MHC II and CD86 on dendritic cells by opposing IL-10-driven MARCH1-mediated ubiquitination and degradation. J. Exp. Med. 208, 149-165 (2011).

35. Eisenberg, S.P. et al. Primary structure and functional expression from complementary DNA of a human interleukin-1 receptor antagonist. Nature 343, 341-346 (1990).

36. Carter, D.B. et al. Purification, cloning, expression and biological characterization of an interleukin-1 receptor antagonist protein. Nature 344, 633-638 (1990)

37. Arrighi, J.F., Rebsamen, M., Rousset, F., Kindler, V. \& Hauser, C. A critical role for p38 mitogen-activated protein kinase in the maturation of human blood-derived dendritic cells induced by lipopolysaccharide, TNF-alpha, and contact sensitizers. J. Immunol. 166, 3837-3845 (2001).

38. Nakahara, T., Moroi, Y., Uchi, H. \& Furue, M. Differential role of MAPK signaling in human dendritic cell maturation and Th1/Th2 engagement. J. Dermatol. Sci. 42, 1-11 (2006).

39. Lu, H.T. et al. Defective IL-12 production in mitogen-activated protein (MAP) kinase kinase 3 (Mkk3)-deficient mice. EMBO J. 18, 1845-1857 (1999).

40. Luperchio, S.A. \& Schauer, D.B. Molecular pathogenesis of Citrobacter rodentium and transmissible murine colonic hyperplasia. Microbes Infect. 3, 333-340 (2001).

41. Mangan, P.R. et al. Transforming growth factor-beta induces development of the $T(H) 17$ lineage. Nature 441, 231-234 (2006).

42. Zheng, Y. et al. Interleukin-22 mediates early host defense against attaching and effacing bacterial pathogens. Nat. Med. 14, 282-289 (2008).

43. Spahn, T.W. et al. The lymphotoxin-beta receptor is critical for control of murine Citrobacter rodentium-induced colitis. Gastroenterology 127, 1463-1473 (2004).

44. Ota, N. et al. IL-22 bridges the lymphotoxin pathway with the maintenance of colonic lymphoid structures during infection with Citrobacter rodentium. Nat. Immunol. 12, 941-948 (2011).

45. Silva, M.A. et al. Dendritic cells and toll-like receptors 2 and 4 in the ileum of Crohn's disease patients. Dig. Dis. Sci. 53, 1917-1928 (2008).

46. Dudziak, D., Nimmerjahn, F., Bornkamm, G.W. \& Laux, G. Alternative splicing generates putative soluble CD83 proteins that inhibit $T$ cell proliferation. J. Immunol. 174, 6672-6676 (2005).

47. Xu, J.F. et al. A limited course of soluble CD83 delays acute cellular rejection of MHC-mismatched mouse skin allografts. Transplant Int. 20, 266-276 (2007).

48. Cramer, S.O. et al. Activation-induced expression of murine CD83 on T cells and identification of a specific CD83 ligand on murine B cells. Int. Immunol. 12, 1347-1351 (2000).

49. Hirano, N. et al. Engagement of CD83 ligand induces prolonged expansion of CD8 + T cells and preferential enrichment for antigen specificity. Blood 107, 1528-1536 (2006).

50. Reinecker, H.C. et al. Monocyte-chemoattractant protein 1 gene expression in intestinal epithelial cells and inflammatory bowel disease mucosa. Gastroenterology 108, 40-50 (1995).

51. Khan, W.I. et al. Critical role of MCP-1 in the pathogenesis of experimental colitis in the context of immune and enterochromaffin cells. Am. J. Physiol. Gastrointest. Liver Physiol. 291, G803-G811 (2006).

52. Hue, S. et al. Interleukin-23 drives innate and T cell-mediated intestinal inflammation. J. Exp. Med. 203, 2473-2483 (2006).

53. Uhlig, H.H. et al. Differential activity of IL-12 and IL-23 in mucosal and systemic innate immune pathology. Immunity 25, 309-318 (2006). 
54. Kobayashi, T. et al. IL23 differentially regulates the Th1/Th17 balance in ulcerative colitis and Crohn's disease. Gut 57, 1682-1689 (2008).

55. Neurath, M.F., Fuss, I., Kelsall, B.L., Stuber, E. \& Strober, W. Antibodies to interleukin 12 abrogate established experimental colitis in mice. J. Exp. Med. 182, 1281-1290 (1995).

56. Fuss, I.J. et al. Anti-interleukin 12 treatment regulates apoptosis of Th1 T cells in experimental colitis in mice. Gastroenterology 117, 1078-1088 (1999).

57. Mannon, P.J. et al. Anti-interleukin-12 antibody for active Crohn's disease. N. Engl. J. Med. 351, 2069-2079 (2004).

58. Klein, E., Koch, S., Borrn, B., Neumann, J., Herzog, V., Koch, N. \& Bieber, T. CD83 localization in a recycling compartment of immature human monocyte-derived dendritic cells. Int. Immuno. 17, 477-487 (2005).

59. Hock, B.D. et al. The soluble form of CD83 is present at elevated levels in a number of hematological malignancies. Leuk. Res. 28, 237-241 (2004).

60. Hock, B.D. et al. Release and clinical significance of soluble CD83 in chronic lymphocytic leukemia. Leuk. Res. 33, 1089-1095 (2009).

61. Warming, S., Rachel, R.A., Jenkins, N.A. \& Copeland, N.G. Zfp423 is required for normal cerebellar development. Mol. Cell Biol. 26, 6913-6922 (2006).

62. Liu, P., Jenkins, N.A. \& Copeland, N.G. A highly efficient recombineeringbased method for generating conditional knockout mutations. Genome Res. 13, 476-484 (2003).
63. Lee, E.C. et al. A highly efficient Escherichia coli-based chromosome engineering system adapted for recombinogenic targeting and subcloning of BAC DNA. Genomics 73, 56-65 (2001).

64. Warming, S., Costantino, N., Court, D.L., Jenkins, N.A. \& Copeland, N.G. Simple and highly efficient BAC recombineering using galK selection. Nucleic Acids Res. 33, e36 (2005).

65. Gertsenstein, M. et al. Efficient generation of germ line transmitting chimeras from C57BL/6N ES cells by aggregation with outbred host embryos. PLoS One 5, e11260 (2010).

66. Crowley, T.E., Hoey, T., Liu, J.K., Jan, Y.N., Jan, L.Y. \& Tjian, R. A new factor related to TATA-binding protein has highly restricted expression patterns in Drosophila. Nature 361, 557-561 (1993).

67. Inaba, K. et al. Generation of large numbers of dendritic cells from mouse bone marrow cultures supplemented with granulocyte/macrophage colony-stimulating factor. J. Exp. Med. 176, 1693-1702 (1992).

68. Eguchi, J. et al. Identification of adipocyte adhesion molecule (ACAM), a novel CTX gene family, implicated in adipocyte maturation and development of obesity. Biochem. J. 387, 343-353 (2005).

(c)(1)(9) This work is licensed under the Creative Commons Attribution-NonCommercial-No

Derivative

Works 3.0 Unported License. To view a copy of this license, visit http://creativecommons.org/licenses/by-nc-nd/3.0/ 